\title{
Atmospheric and ionospheric coupling phenomena associated with large earthquakes
}

\author{
M. Parrot ${ }^{1, a}$, V. Tramutoli ${ }^{2}$, Tiger J.Y. Liu ${ }^{3}$, S. Pulinets ${ }^{4}$, D. Ouzounov ${ }^{5}$, \\ N. Genzano ${ }^{2}$, M. Lisi ${ }^{2}$, K. Hattori ${ }^{6}$, and A. Namgaladze ${ }^{7}$ \\ ${ }^{1}$ LPC2E/CNRS, Orléans 45045, France \\ ${ }^{2}$ University of Basilicata, 85100 Potenza, Italy \\ ${ }^{3}$ National Central University, 32001 Taoyuan, Taiwan \\ ${ }^{4}$ Space Research Institute, 117810 Moscow, Russia \\ ${ }^{5}$ Chapman University, 92866 Orange, USA \\ ${ }^{6}$ Graduate School of Science, Chiba University, Chiba 263-8522, Japan \\ ${ }^{7}$ Murmansk State Technical University, 183010 Murmansk, Russia
}

\begin{abstract}
This paper explores multi-instrument space-borne observations in order to validate physical concepts of Lithosphere-AtmosphereIonosphere Coupling (LAIC) in relation to a selection of major seismic events. In this study we apply some validated techniques to observations in order to identify atmospheric and ionospheric precursors associated with some of recent most destructive earthquakes: M8.6 of March 28, 2005 and M8.5 of Sept. 12, 2007 in Sumatra, and M7.9 of May 12, 2008 in Wenchuan, China. New investigations are also presented concerning these three earthquakes and for the M7.2 of March 2008 in the Xinjiang-Xizang border region, China (the Yutian earthquake). It concerns the ionospheric density, the Global Ionospheric Maps (GIM) of the Total Electron Content (TEC), the Thermal InfraRed (TIR) anomalies, and the Outgoing Longwave Radiation (OLR) data. It is shown that all these anomalies are identified as short-term precursors, which can be explained by the LAIC concept proposed in [S. Pulinets, D. Ouzounov, J. Asian Earth Sci. 41, 371 (2011)].
\end{abstract}

\section{Introduction}

Since old times there are many reports about earthquakes accompanied and even preceded by abnormal phenomena involving magnetism and electricity ([2]). But these observations have suffered from a lack of precise measurements and quantification. It is not the case these days because seismic areas are well equipped (particularly in China) with a lot of various experiments, which measure many different parameters. Moreover, there are satellites to observe the Earth in a broad range of wavelengths from infrared to radio waves. These satellites register parameters all around the Earth, it is possible to compare ground-based and satellite data at the time of large events. It was shown that many parameters significantly change in the atmosphere

a e-mail: mparrot@cnrs-orleans.fr 
and in the ionosphere from a few hours up to a few days before earthquakes $([3,4]$, and references therein). At the same time, models to explain this coupling between the lithosphere-atmosphere-ionosphere have been developed [1,5-14].

The aim of this paper is to review precursory effects before a selection of large earthquakes in order to deduce generalities to validate Lithosphere-AtmosphereIonosphere Coupling (LAIC) models. These models are discussed in Section 2. The methodology to process the data is described in Section 3. New complementary analyses have also been done. Abnormal variations of atmospheric and ionospheric parameters observed before powerful earthquakes are presented in Section 4 (Sumatra, 2005; Sumatra, 2007; Yutian, 2008; Wenchuan, 2008), whereas discussions and conclusions are given in Section 5 .

\section{The LAIC concept}

The different precursors that have been observed before earthquakes by many experiments can be linked through various mechanisms in the atmosphere and the ionosphere. Then, the same hypotheses of generation mechanism of these precursors are valid for different perturbations. LAIC models have been widely developed in several papers (example $[1,6,7,15,16]$ ). The lithospheric-atmospheric-ionosphericmagnetospheric (LAIMC) coupling mechanism, theorizes that the primary process of EM disturbance observed before large seismic events (volcanoes) is the air ionization produced by increased emanation of gases (radon, CO2, methane) from the Earth's crust in the vicinity of active tectonic faults before an earthquake [17], which triggers reactions from the ground level up to the ionosphere and magnetosphere of the Earth. This ionization leads to a change of the air conductivity. Then, many different effects can occur: growth of air temperature, formation of temperature and pressure anomalies, anomalies in Outgoing Longwave infrared Radiation (OLR), redistribution of electric charges in the Earth's atmospheric system and then in the ionosphere due to the global electric circuit [9], and apparition of anomalous electric field. The ionosphere reacts to the changes of electric properties of the near-ground layer, and the electric field induced within the ionosphere causes ion drift and the creation of irregularities of electron concentration. Local variations of ionosphere potential lead to formation of irregularities of electron and ion concentration, stimulation of plasma instabilities leading to variations of plasma temperature and ion composition as well as generation of electromagnetic (EM) emissions. Joule heating at altitudes of maximum ionosphere conductivity can lead to generation of acoustic gravity waves. Due to high conductivity along geomagnetic field lines the plasma turbulence from ionospheric altitudes will be projected into the magnetosphere and magnetically conjugated region.

It is expected that the mechanism described in the LAIC model starts to be active when some parameters exceed a threshold value which means that the system approaches to a critical state.

Outside of gas emanation increase, there are other LAIC models [7]. The most well-known is the Freund's model because it is based on many reliable laboratory experiments where various rock samples are stressed under different conditions by an hydraulic press $[8,18-21]$. He claims that the increased conductivity due to the positive hole charge carriers activated by the stressed rocks could generate a current flow between the ground and the bottom of the ionosphere. Comparison between these two models has been earlier discussed in [15] and more recently in [7]. The gas emanation model gives an electric field value in the ionosphere of the order of $0.1-1 \mathrm{mV} / \mathrm{m}$ which has been confirmed by a recent experimental measurement [22], while in the Freund's model it is at least one order of magnitude larger. It cannot 
be ruled out that both models could be valid depending on the crust composition. But the main drawback of the Freund's model is that it is not valid for earthquakes occurring in the open sea, and the statistical analyses performed with DEMETER data have shown that the number of ionospheric anomalies is at least as large for open sea earthquakes as for land earthquakes [23,24].

\section{Methodology}

To test the completeness of the LAIC concept we propose to validate the synergy between the ionospheric and thermal transient fields through their dynamic development during the lithospheric-atmospheric coupling. Because of the record of data all around the Earth, EM satellites, remote sensing, and GPS observations offer a good opportunity to study on continuous basis the atmosphere-ionospheric phenomena related to earthquake preparation processes. We briefly examined six different physical observations characterizing the state of the atmosphere/ionosphere during the periods before and after major earthquake activities: 1. EM data from DEMETER mission; 2. Equatorial Ionospheric Anomalies (EIA); 3. GPS/TEC (Total Electron Content) ionospheric variability; 4. Satellite Thermal InfraRed (TIR) anomalies; 5. Atmospheric chemical potential (ACP); and 6. Outgoing Long wave Radiation, and OLR (infra-red 10-13 $\mu \mathrm{m}$ ) measured at the top of the atmosphere. More details can be found in a new published book [25].

\subsection{The DEMETER EM data}

DEMETER was an ionospheric micro-satellite in operation between June 2004 and December 2010. Its orbit was circular $(660 \mathrm{~km})$, polar, and nearly sun-synchronous (10.30 LT and 22.30 LT). Its payload measured electromagnetic waves in different frequency ranges from ULF to MF, and also plasma parameters (for example the electron and ion densities). The description of the experiments onboard the satellite can be found in [26].

\subsection{Equatorial ionospheric anomalies}

One of the most spectacular features in the ionosphere is the equatorial ionization anomaly (EIA). The EIA is characterized by two enhanced plasma (or electron density, TEC, etc.) crests at low latitudes straddling the magnetic equator with the electron density depleted on the magnetic equator. It is the region that yields the greatest electron density on the globe. The EIA is produced by the equatorial plasma fountain, which lifts the plasma from magnetic equator to higher altitudes and then it diffuses down along magnetic field lines to higher latitudes creating two ionization crests on both sides of the magnetic equator [27-34]. Thus, the EIA is a daily normal feature at low latitudes straddling the magnetic equator with the depletion on the magnetic equator. Then no peak at low latitudes means that the EIA is disappearing and it is an indication of earthquake preparation process influences. This is due to the action of the external electric field which is triggered at this time $[15,35,36]$.

\subsection{GPS Total Electron Contents anomalies}

To detect anomalous signals of the GPS TEC variations, a quartile-based process is performed. At each time point, we compute the median $M$ of every preceding 
fifteen-day of the GPS TEC as well as find the deviation between the observed one on the sixteen day and the computed median $M$. To provide the information about the deviation, we also calculate the first (or lower) and the third (or upper) quartiles, denoted by LQ and UQ, respectively. Note that assuming a normal distribution with mean $m$ and standard deviation $\sigma$ for the GPS TEC, the expected values of LQ and UQ should be $m-0.67 \sigma$ and $m+0.67 \sigma$, respectively [37]. To have a stringent criterion, we set the lower bound, LB $=M-1.5(M-\mathrm{LQ})$ and the upper bound, $\mathrm{UB}=M+1.5(\mathrm{UQ}-M)$. Therefore, the probability of a new GPS TEC in the interval (LB, UB) is approximately $68 \%$. The median together with the associated LB and UB then provide references for the GPS TEC variations on the sixteen day. When an observed GPS TEC on the sixteen day is not in the associated interval (LB, UB), we declare an upper (increase) or lower (decrease) abnormal GPS TEC signal. The GPS TEC time resolution is two-hours, and a criterion is defined to claim that we are faced with an anomalous day. If during more than 8 successive hours, upper (lower) abnormal signals appear in a day, and if these observed GPS TEC are greater (smaller) than the associated UB (LB), we then consider that an upper (lower) anomalous day is detected, i.e. we have a positive (negative) anomaly [38].

\subsection{Satellite Thermal InfraRed (TIR) anomalies}

Anomalies in the Earth's thermally emitted radiations, as measured by the MTSAT satellite operating in the TIR (Thermal InfraRed) spectral band, have been also observed in apparent relation with events. The approach proposed in $[39,40,98,99]$ was applied to MTSAT TIR radiances collected over the area since 2005 in order to isolate Significant Sequences of TIR Anomalies (SSTAs) from normal signal variations as well as to exclude spurious effects ([13] and reference therein). Following their definition (e.g. $[13,41,42])$ an SSTA occurs when a significant TIR signal excess $(>3 \sigma$ compared with its expected value) appears persistently in space (at least $150 \mathrm{~km}^{2}$ are affected) and in time domain (at least one repetition in a week). Long-term correlation analyses among SSTAs and earthquakes $(M>4)$ were performed in [41] over Greece (10 years, 2004-2013), in [42] over Taiwan (8 years, 1995-2002), and in [13] over Italy (1 year, 2012-2013). In those cases, a positive correlation was assumed for SSTAs occurring within a space-time window of 45 days (starting 30 days before the quake ending 15 days after) and within a distance $\mathrm{D}\left(D<R_{D}\right.$ where $R_{D}$ is the Dobrovolsky distance, $R_{D}=10^{0.43 M} \mathrm{~km}$, and $\min (D)=150 \mathrm{~km}$ whatever the value of $M$ is) from earthquakes of magnitude $M$.

\subsection{Atmospheric chemical potential}

As a possible parameter, we consider a correction of the chemical potential of water vapor at a high level of ionization. It was showed in [5] that the latent heat for water molecules at phase transitions is equal to its chemical potential or to the work function when the molecule separates from water droplet. The atmospheric chemical potential correction can be expressed using the air temperature at the Earth's surface and the relative air humidity [6]. It was possible to evaluate this parameter for some earthquakes under studies in this paper.

\subsection{Satellite Outgoing Longwave Radiation anomalies}

The OLR is measured at the top of the atmosphere (TOA) and integrates the emissions from the ground, lower atmosphere and clouds [43]. It has been primary used 
Table 1. List of studied earthquakes (USGS).

\begin{tabular}{llllll}
\hline Name & Location & Geographic lat/lon $\left(^{\circ}\right)$ & Date \& Time (UTC) & $\mathrm{M}$ & $\mathrm{H}(\mathrm{km})$ \\
\hline 1 & Nias, Sumatra, Indonesia & $2^{\circ} 04^{\prime} 35^{\prime \prime} \mathrm{N} 97^{\circ} 00^{\prime} 58^{\prime \prime} \mathrm{E}$ & 28 March 2005 16:09:36 & 8.6 & 30 \\
2 & Sumatra, Indonesia & $4.520^{\circ} \mathrm{S} 101.374^{\circ} \mathrm{E}$ & 12 Sept 2007 11:10:26 & 8.5 & 30 \\
3 & Yutian, Xinjiang-Xizang & $35.49^{\circ} \mathrm{N}, 81.46^{\circ} \mathrm{E}$ & 20 March 2008 22:32:57 & 7.2 & 10 \\
& China & & & & \\
& & & & \\
& Wenchuan, Sichuan, China & $31.021^{\circ} \mathrm{N} 103.367^{\circ} \mathrm{E}$ & 12 May 2008 06:28:01 & 8.0 & 9 \\
\hline
\end{tabular}

to study Earth radiative budget and climate [44,45]. In this paper we study the OLR in the range of 8-12 microns. A daily mean data footprint covering a significant area $\left(90^{\circ} \mathrm{N}-90^{\circ} \mathrm{S}, 0^{\circ} \mathrm{E}\right.$ to $\left.357.5^{\circ} \mathrm{E}\right)$ with a spatial resolution of $2.5^{\circ}$ by $2.5^{\circ}$ was used to study the OLR variability in the zone of earthquake activity [46-48]. An increase in radiation and a transient change in OLR were recorded at the top of the atmosphere over seismically active regions and were proposed to be related to thermodynamic processes at the Earth's surface. The OLR anomalous variations were defined in [46] as an index (Fig. 1 right). This index is similar to the definition of an anomalous thermal field proposed in [40].

\section{Case studies}

To illustrate the possible atmosphere-ionosphere coupling link with pre-earthquake processes we explored 4 strong earthquakes (M7.2-M8.6) for last 10 years (20052008) shown in Table 1. We present results of our recent analysis of satellite EM data, GPS/TEC, satellite observed thermal radiation acquired daily in the regions of recent major earthquakes, and discuss the evidence in relation to the earthquake events. We have chosen these earthquakes as they are the strongest earthquakes observed during the DEMETER mission, and also because they represent different seismo-tectonic and meteorological conditions. This allows to check if anomalies are present whatever these conditions are. Other selection criteria are related to the availability of simultaneous data sets of atmospheric and ionospheric parameters, and the lack of other events likely to perturb the ionosphere (for example solar activity).

\subsection{The M8.6 Nias Earthquake of March 28, 2005}

The 2005 Sumatra earthquake, also called the Nias Earthquake occurred at 16:09:36 UTC (23:09:36 LT) on 28 March 2005 with a magnitude of about 8.6. The hypocenter was located at $2^{\circ} 04^{\prime} 35^{\prime \prime} \mathrm{N} 97^{\circ} 00^{\prime} 58^{\prime \prime} \mathrm{E}, 30 \mathrm{~km}$ below the surface of the Indian Ocean (Fig. 1 left). This earthquake generated a small tsunami relatively to the 2004 Sumatra earthquake.

From our most recent OLR analysis we used the NOAA-15 daily $2.5^{\circ} \times 2.5^{\circ}$ grided data to explore temporal and spatial variability of OLR prior to the March 28 earthquake. The maximum for the entire month in the area of $2^{\circ} \mathrm{N}-7^{\circ} \mathrm{N}, 92^{\circ}-95^{\circ} \mathrm{E}$ is located at $4.5^{\circ} \mathrm{N}, 95^{\circ} \mathrm{E}$ and reached a value of $+18.6 \mathrm{~W} / \mathrm{m}^{2}$ on March 15 (13 days in advance). The location of the OLR anomaly is 1.5 pixels away from the epicentral region (Fig. 1 right). It fits well with the stressed area shown in Figure 1 left. This anomaly is the largest positive value observed over the epicentral area for 2001-2005. Additional low OLR values dominating the epicentral area are found between March 15 and March 25, which indicates coherence in spatial variability of low OLR field.

OLR anomaly can occur over water. Upwelling from the sea bottom is chaotic turbulence triggered by gas released from the bottom as the leading causes of the 

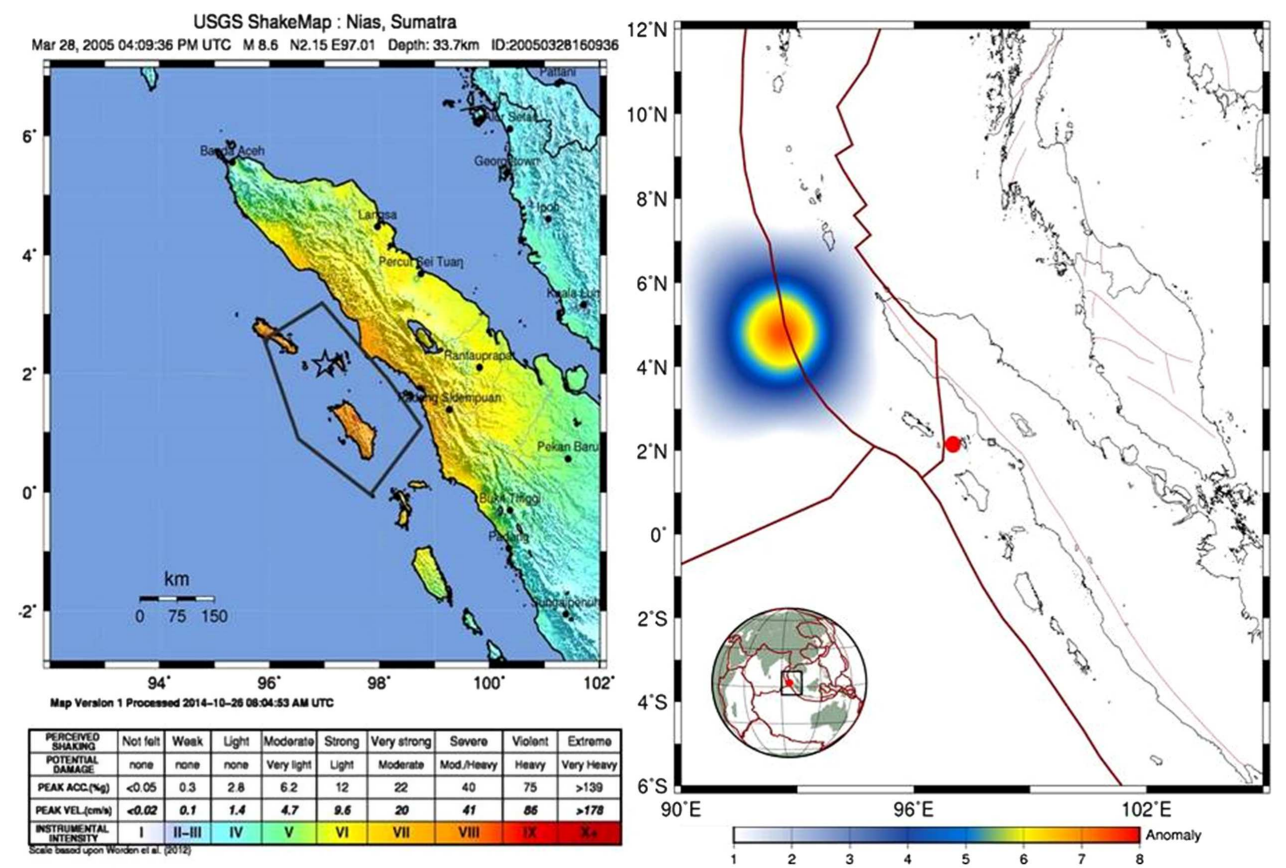

Fig. 1. Left: shake map showing the extent of the ruptured fault lines for the 2005 Nias earthquake (USGS). Right: satellite OLR (NOAA15 data) of March 15, 2005. Main faults are shown. The anomaly is color coded according to the scale below. The units are in $\mathrm{Wm}^{-2}$.

observed anomalies over the water. After the gas has been released in the atmosphere, the same mechanism of generating the OLR anomalies follows. Only intense gas discharges (including the underwater gas discharges), as it is described in [49] provide gas radon/methane transport in the water. The presence of radon in coastal and open ocean waters was demonstrated experimentally [50,51]. The color scale in Fig. 1 right represents the OLR anomaly for OLR (infra-red 10-12 $\mu \mathrm{m}$ ) measured at the TOA $(8-12 \mathrm{~km})$ not on the land or sea surface. The methodology is described in [25].

The anomalous change in the outgoing thermal radiation (OLR), not temperature, is a result of atmospheric effects linked to air ionization described before and not of increased surface temperature [52]. In the cases under clear sky condition, water vapor is a significant factor that has strong absorption, and re-emission capabilities could be registered in the longwave part of the infrared emission within the transparency window of the atmosphere $8-12 \mu \mathrm{m}$. In the case of cloud cover, because of the general atmospheric circulation, the top of the clouds re-emitting the infrared energy as OLR at TOA. In both cases of sky conditions, the latent heat generated in the atmosphere triggered emission or re-emission (at TOA) of longwave ongoing thermal radiation in a wide range of 8-12-micron spectral window.

According to [53] the electron density showed two types of anomalies: one being monotone increase in the single peak values with amplitudes exceeding $1 \sigma$ such as on March 20 and 28,2005, the other one changing the normal single peak to double crest and trough in the equatorial area which occurred on March 22 and 23, 2005.

In this paper the TEC has been investigated using the GIM (Global Ionospheric Maps). GIM TEC maps are the matrix presenting the global distribution of TEC in the form of IONEX index (IONosphere map Exchange) every two hours within the interval $\pm 80^{\circ}$ of latitude and $0^{\circ}-360^{\circ}$ of longitude, and with a resolution of $2.5^{\circ}$ in latitude and $5^{\circ}$ in longitude. The GIM TEC data show in Figure 2 that the TEC 

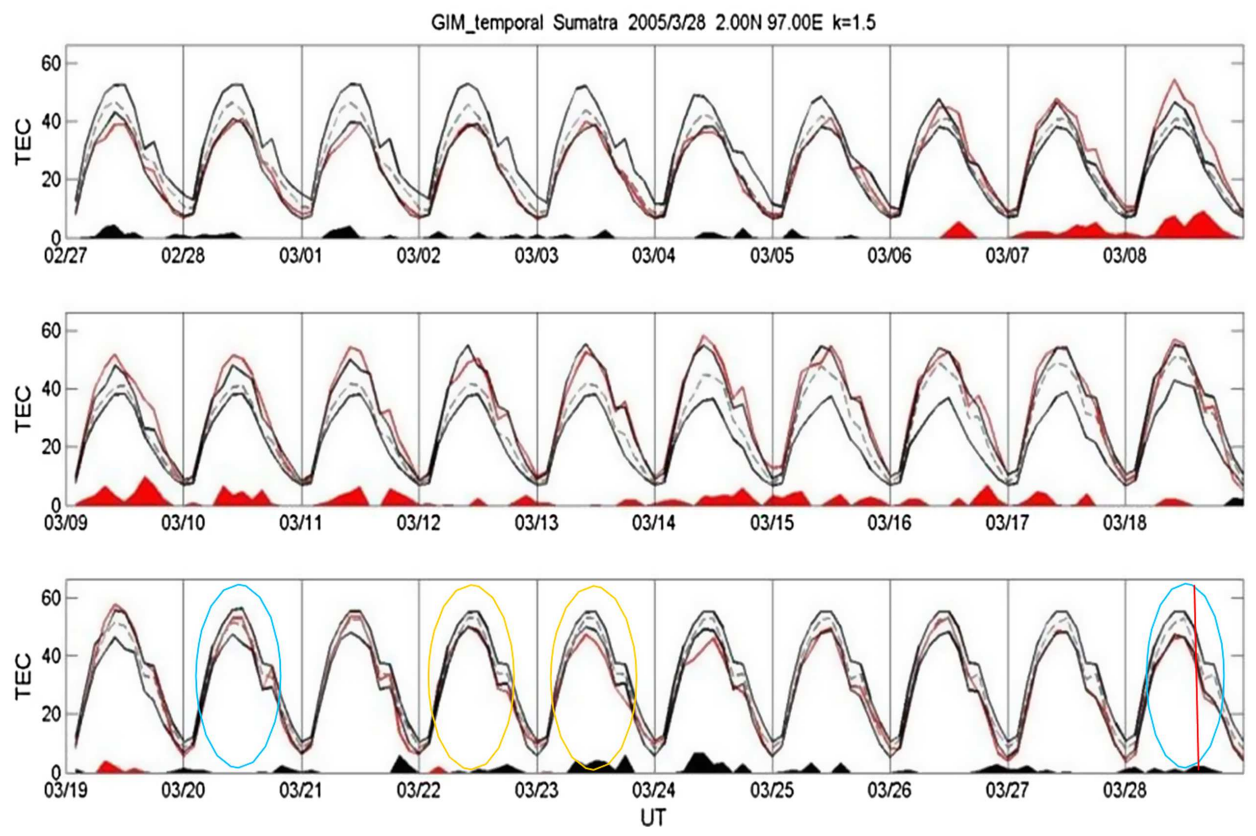

Fig. 2. GIM TEC data in TECu recorded between February 27 and March 28, 2005. The red, blue, and two black curves denote the GIM TEC, associated median, and upper/lower bound (UB/LB), respectively. The LB and UB are constructed by the $1-15$ previous days with moving median $(M)$, lower quartile (LQ), and upper quartile (UQ). Here, $\mathrm{LB}=M-$ $1.5(M-\mathrm{LQ})$ and $\mathrm{UB}=M+1.5(\mathrm{UQ}-M)$. Red and black shaded areas denote differences of $O-\mathrm{UB}$ and LB- $O$, respectively, where $O$ is observed GPS TEC (for more details see the text and [38]). The red vertical line indicates the time of the earthquake.

over the epicenter significantly decreases relatively to LB during 22-24 March but is normal on 20 March. Figure 3 shows the GIM TEC along the $97^{\circ} \mathrm{E}$ longitude (longitude of the Nias earthquake) during the period March 10 - April 7, 2005. The top right panel of Figure 3 presents latitudinal cross-section data from the IONEX table taken at the longitude closest to the earthquake epicenter $\left(95^{\circ}\right)$. To see the equatorial anomaly in the phase of its maximum development, the IONEX map is taken at $14.00 \mathrm{LT}$. The magnetic equator should be around $7-8^{\circ} \mathrm{N}$ latitude and therefore the EIA (Equatorial Ionospheric Anomaly) crest should be $13^{\circ} \mathrm{N}$ to $18^{\circ} \mathrm{N}$ and $7^{\circ} \mathrm{S}$ to $12^{\circ} \mathrm{S}$. The two bottom panels of Figure 3 are the GIM TEC (same as in the top right panel but for several days) and associated variation normalized by the standard deviation, respectively. The lower panel reveals that the northern and southern EIA crests significantly increase $(\sim 2 \sigma)$ on March 22 and 23 . It can be seen that there is no obvious feature on March 20 and 28.

Other authors have also noticed this EIA variation. The ionospheric variations using GPS (Global Positioning System) and CHAMP data have been investigated in [54]. With the electron density they have shown that an equatorial anomaly modification took place a few days before the event. This modification appeared under the form of crest amplification during the daytime. The EIA strength with the DEMETER and CHAMP data has been studied in [35]. They have shown that the EIA was intensified along the orbits whose longitudes were close to the epicenter within about a week before and after occurrence of the earthquake during daytime.

It has been noted in [15] that plasma bubbles were registered every day at night time (22 LT) one week before the main shock, and then disappeared. He observed 

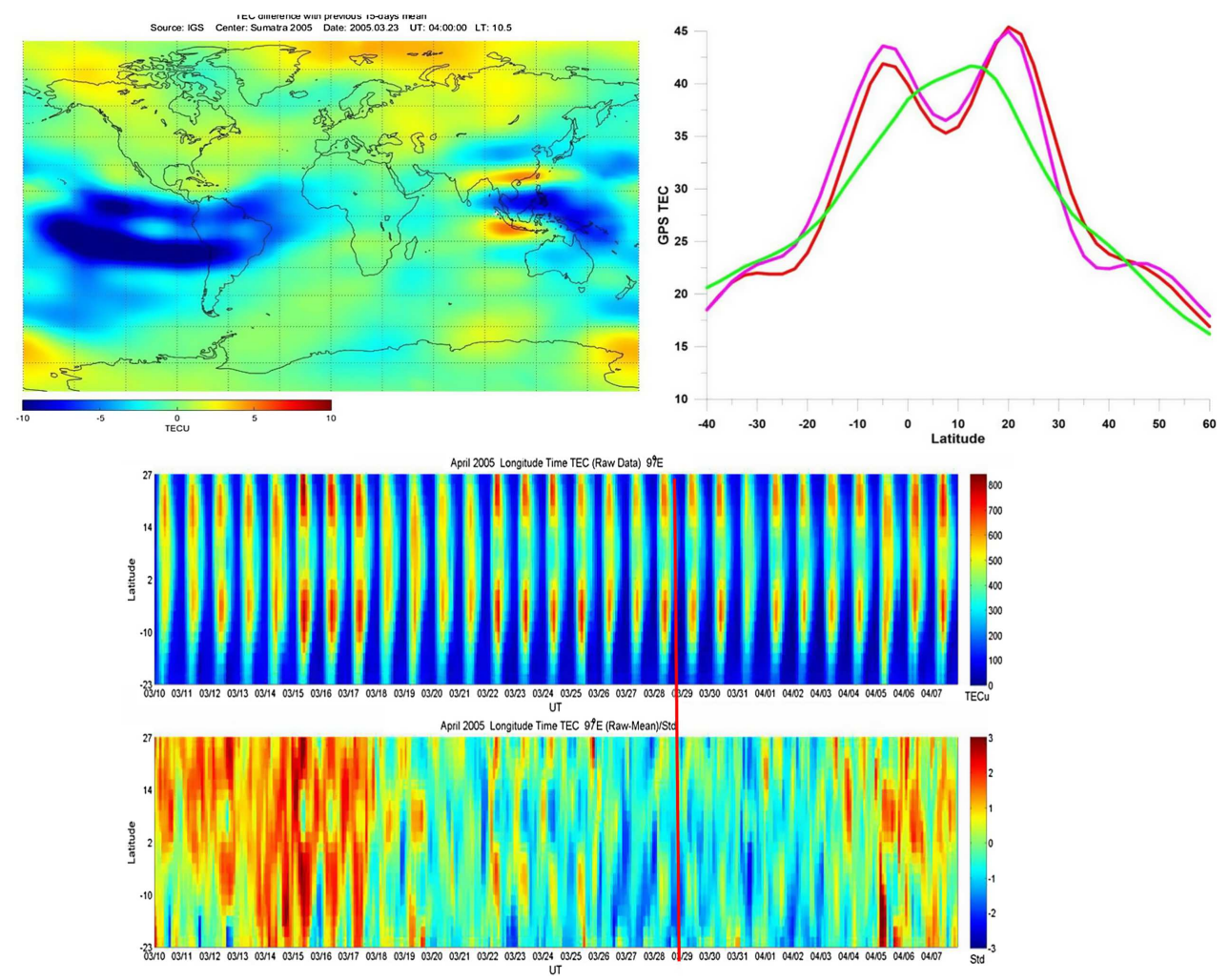

Fig. 3. Top left: differential GIM map for March 23 (five days before the earthquake) at 10.5 LT; Top right: GPS TEC variations in TECu as function of the latitude. It shows the formation of equatorial anomaly 5 (magenta) and 4 (red) days before the Sumatra 2005 (Nias) earthquake. The shape of equatorial region in undisturbed conditions (13 March) is shown by the green line. The two bottom panels are related to the values of the GIM TEC along the $97^{\circ} \mathrm{E}$ longitude during the time interval March 10 - April 7, 2005 (the panel below corresponds to the relative variation). The red line indicates the time of the earthquake.

the formation of crests of the equatorial anomaly and two depletions equatorward from the crests at both sides from the geomagnetic equator. He noticed that at the altitude of DEMETER $(710 \mathrm{~km})$ the formation of crests was itself anomalous. Usually at these altitudes the equatorial distribution of plasma density has a single peak over the geomagnetic equator. An extremely high vertical plasma drift must be considered to explain this perturbation.

In addition to DEMETER morning passes demonstrating the formation of the equatorial anomaly before the Sumatra 2005 earthquake we analyzed the latitudinal cross-sections using the GIM maps. For the precursor's identification it is important to cross-validate the results by the different techniques of ionosphere monitoring. The only limitation is that GIM maps up to date were generated by IGS every two hours, so 10 LT is unavailable, and we used the 10.5 LT map when some intimation of the EIA may appear. The latitudinal cross-sections for 4 (red) and 5 (magenta) days before the earthquake at the epicenter longitude which are presented in Figure 3 top right indicate an abnormal formation of the EIA. Oppositely, the equatorial region shape in undisturbed conditions (13 March) shown by a green line indicates that in natural conditions the EIA is not observed in the morning. 

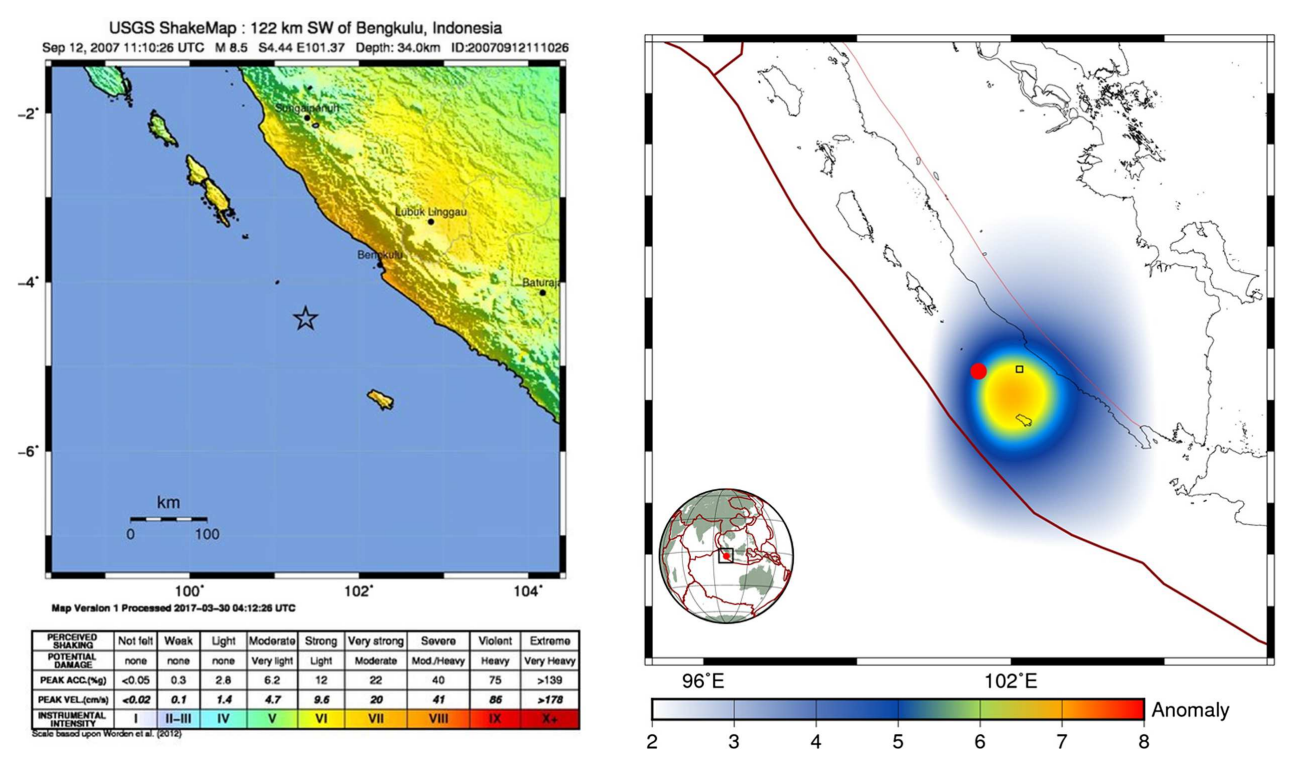

Fig. 4. Left: shake map showing the extent of the ruptured fault lines for 2007 Sumatra earthquake (USGS). Right: satellite OLR (NOAA15 data) of Sept 2, 2007.

Determination of the location of the variations is possible by application of mapping technique. This is usually made by constructing the GIM maps for the given time period. We use the differential maps for detection [55]. We look for anomalies appearing in the images and how close they are to the earthquake epicenter. This is demonstrated in the top left panel of Figure 3 which corresponds to a differential map calculated for March 23, i.e. five days before the earthquake.

Concerning this earthquake, particle and wave anomalies have been also detected. Six days before, bursts of precipitating electrons were detected in [56] using the DEMETER data. With the same DEMETER data, a statistical analysis has been performed in [57] with 69 strong earthquakes with a magnitude above 7.0 during January 2005 to February 2010, and thus including the Sumatra earthquakes. They claimed that electrostatic perturbations in the ULF range $(<250 \mathrm{~Hz})$ are observed in the equatorial region. They have shown data recorded 20 minutes before the 28 March 2005 Sumatra earthquake at less than $2000 \mathrm{~km}$ which present this particularity together with electron density, electron temperature, and ion density variations.

\subsection{The M8.5 September 12, 2007 in Sumatra}

The 2007 Sumatra earthquake was in fact a series of three major earthquakes. The first earthquake occurred at 11:10:26 UTC (18:10 LT) on 12 September 2007, with a magnitude of 8.5 . It was located at $4.520^{\circ} \mathrm{S} 101.374^{\circ} \mathrm{E}$ with a depth of $34 \mathrm{~km}$ (see Figure 4 left). The second largest earthquake with a magnitude equal to 7.9 occurred later the same day at 23:49:04 UT (06:49:04 LT the following day). It was centered at $2.506^{\circ} \mathrm{S} 100.906^{\circ} \mathrm{E}$ with a depth of $10 \mathrm{~km}$. A third earthquake with a magnitude equal to 7.0 occurred at 03:35:26 UTC (10:35:26 LT) on 13 September. It was centered at $2.160^{\circ} \mathrm{S} 99.851^{\circ} \mathrm{E}$ with a depth of $10 \mathrm{~km}$. There were many aftershocks with magnitude larger than 6 on 13, 14 and 20 September.

We used the NPOESS daily data from NOAA-15 to explore temporal and spatial variability of OLR prior to the M8.5 of September 12. The maximum in the area of 

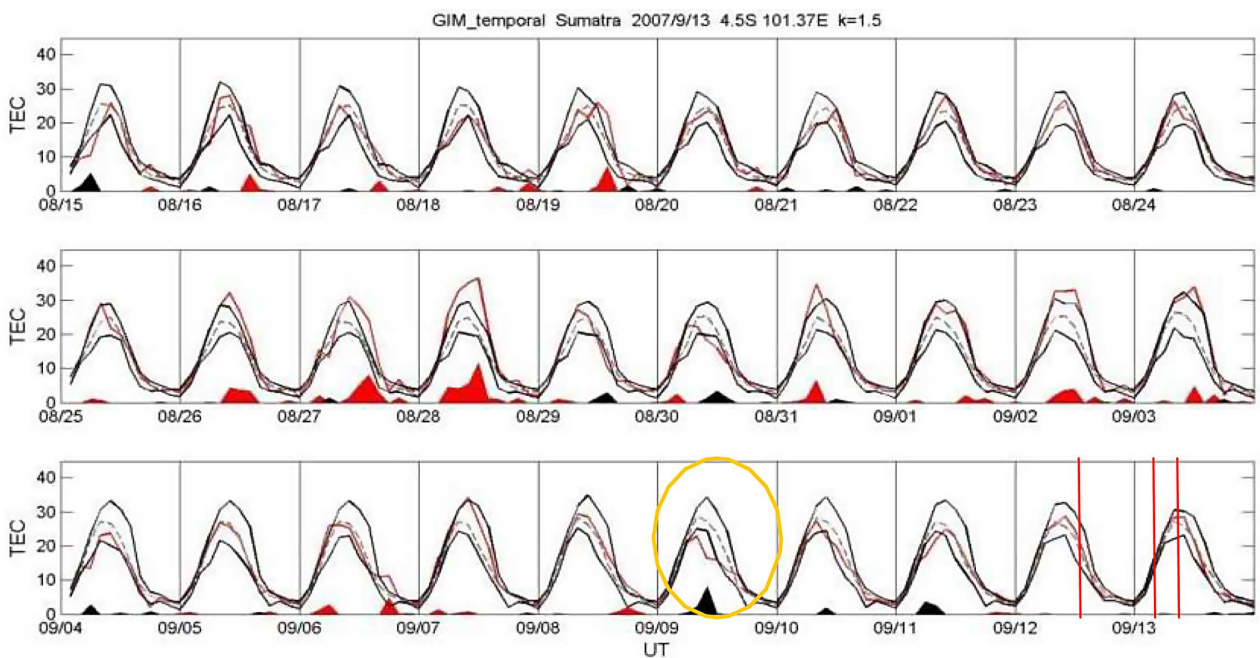

Fig. 5. Similar to Figure 2 but for GIM TEC data recorded between August 15 and September 13,2007 . The red lines indicate the time of the shock and the two main aftershocks.

$10^{\circ} \mathrm{S}-2^{\circ} \mathrm{N}, 95^{\circ}-108^{\circ} \mathrm{E}$ is located near $5^{\circ} \mathrm{S}, 102^{\circ} \mathrm{E}$. This was also the largest increase for the entire 2001-2007 periods in the OLR field. On Sep 2, an anomaly occurred near the epicentral area $\left(4.520^{\circ} \mathrm{S}, 101.374^{\circ} \mathrm{E}\right), 10$ days before the main event (Fig. 4 right). This anomaly is the largest positive nighttime OLR increase $(4 \sigma)$ over the epicentral area observed during the month of September 2007.

It has been established in [58] that three days before the earthquake at 14:00 to 15:00 LT, a strong negative TEC anomaly was detected around the earthquake epicenter. They have also investigated the three-dimensional structure of electron density in the ionosphere, using a tomographic approach. Their results have indicated a significant decrease of electron density taking place at altitudes of 250 to $400 \mathrm{~km}$, especially at an altitude of $330 \mathrm{~km}$.

As before the GIM TEC has been investigated for this earthquake and it is shown in Figure 5 that the TEC over the epicenter significantly decreases on September 9, around the noontime period, i.e., three days before the earthquake, which well agrees with the result reported in [58].

The GIM TEC along the $101^{\circ} \mathrm{E}$ longitude has been extracted during the period August 25 - September 22, 2007. The magnetic equator should be around $7-8^{\circ} \mathrm{N}$. The bottom panels of Figure 6 are the GIM TEC and associated variation normalized by the standard deviation, respectively. The lower panel reveals that the TEC significantly decrease $(3 \sigma)$ between $5^{\circ} \mathrm{N}$ and $10^{\circ} \mathrm{S}$. Therefore, the TEC significantly decrease around and south side the epicenter on September.

Normally, in the DEMETER data we cannot find the formation of a double hump structure at the altitude of $660 \mathrm{~km}$ because this altitude is too high, nevertheless, it is observed in GPS TEC. In the top right panel of Figure 6 one can see a picture similar to Figure 3 for the same local time. As a reference we took two profiles before (3 September, green) and after (20 September, dark green) the earthquake.

It is shown that the EIA is abnormally developed 5 (7 September, magenta) and 6 (6 September, red) days before the earthquake. In the top left panel of Figure 6 we also present the differential map for 07 September 2007, which shows the location of the anomaly.

The TEC with a regional network of GPS receivers has been measured in [59]. They have determined that this earthquake, which occurred during a period of quiet 

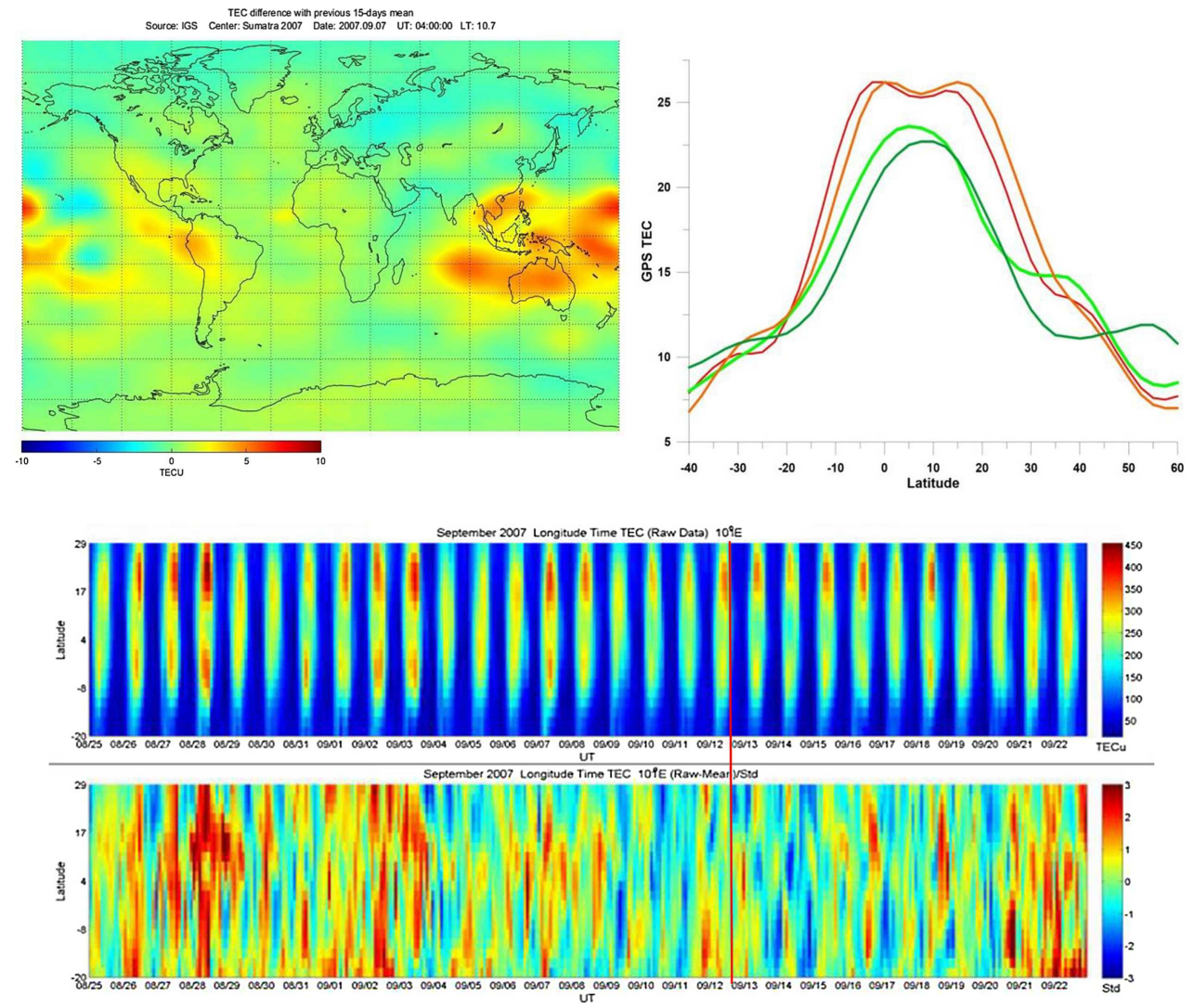

Fig. 6. Top left: differential GIM map for 07 Sept. (five days before the earthquake) at 10.7 LT. Top right: formation of equatorial anomaly 5 (magenta) and 6 (red) days before the Sumatra 2007 earthquake. The shape of equatorial region in undisturbed conditions (3 Sept., green) and 20 Sept. (dark green) are also shown. Bottom: similar to Figure 3 but for the time interval Aug. 25 - Sept. 22, 2007 and along the $101^{\circ} \mathrm{E}$ longitude. The red line indicates the earthquake day.

geomagnetic activity, showed clear positive and negative anomalies starting 30-60 min before the earthquake to the north and the south of the fault region, respectively.

An example of ionospheric perturbations registered by DEMETER during night time on September 10, 2007 (two days before the main earthquake) is shown in Figure 7.

\subsection{The M7.2 March 21, 2008 Yutian earthquake}

This M7.2 earthquake called the Yutian earthquake occurred in the Xinjiang-Xizang border region on March 21, 2008 at 6.33 LT (March 20, 22.33 UT). The location of the epicenter shown in Figure 8 was $\left(35.6^{\circ} \mathrm{N}, 81.6^{\circ} \mathrm{E}\right)$.

Concerning the atmospheric chemical potential, we observe the same situation as for the Wenchuan earthquake (see Sect. 4.4), but the fault is different. The main OLR activity is observed at 1 degree North from the epicenter (Fig. 8 right). The time series and spatial distribution of the chemical potential five days before the earthquake are shown in Figure 9. 


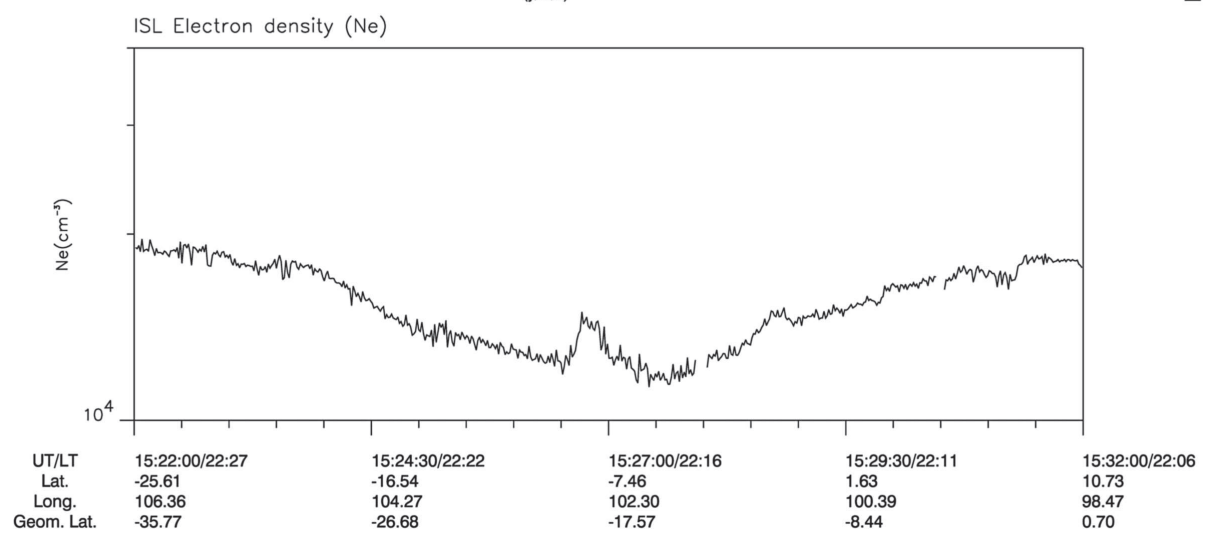

Fig. 7. Electron density recorded by DEMETER on September 10, 2007 between 15.22 and 15.32 UT. The parameters below the plot are the geographic latitude and longitude, and the geomagnetic latitude. The closest approach to the earthquake epicenter is at 15.28 UT.
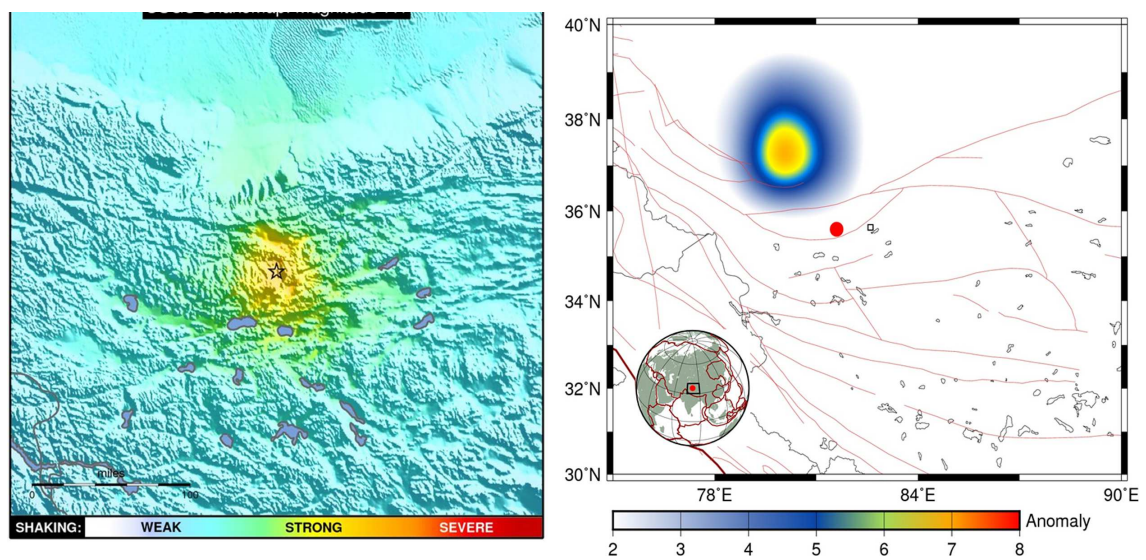

Fig. 8. Left: shake map showing the extent of the ruptured fault lines for the 2008 Yutian earthquake (USGS). Right: satellite OLR (NOAA15 data) of March 18, 2008.

In the case of this M7.2 earthquake of March 21, 2008, NOAA-15 OLR survey for January-December (Figs. 8 right and 10) shows that the initial indication of building an atmospheric anomaly (plotted in red in Fig. 10 top) was detected in the beginning of March and the maximum was reached on March 18 west ward from the epicenter along the Altyn Tagh fault (three days before the main shock). The OLR reference field was built for the entire period of 2004-2008.

The GIM shows that the TEC over the epicenter significantly increases during the period of May 16-21, i.e. 5 to 0 days before the earthquake (Fig. 11). In this Figure 11, the GIM TEC along the $81^{\circ} \mathrm{E}$ longitude is extracted during the period of May 331,2008 . The magnetic equator should be around $3^{\circ} \mathrm{N}$. The top and lower panels are the GIM TEC and associated variation normalized by the standard deviation, respectively. The lower panel reveals that the TEC significantly increased $(3 \sigma)$ around the epicenter during the period of May 16-23. One can notice that the GIM TEC significantly increased over the epicenter on May 17.

An example of ionospheric perturbations registered by DEMETER during night time on March 12, 2008 (eight days before the main earthquake) is shown in Figure 12. 

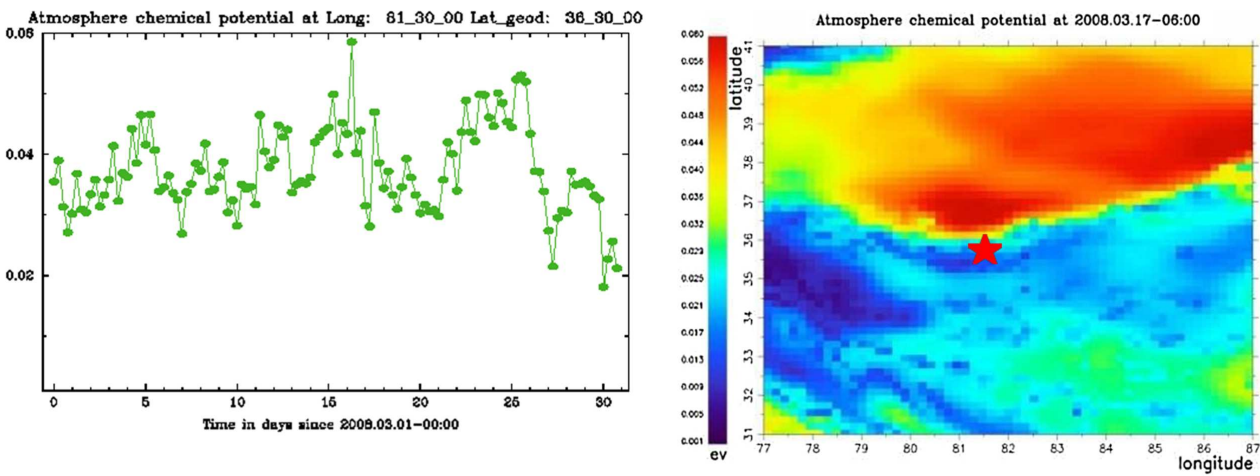

Fig. 9. Left panel - temporal dynamics of the correction to chemical potential at the point $36.5^{\circ} \mathrm{N}, 81.5^{\circ} \mathrm{E}$ (unit is eV); right panel - spatial distribution of the correction to chemical potential on 17 March 2008, i.e. 5 days before the Yutian earthquake. The red star indicates the position of the epicenter.

\subsection{The Wenchuan earthquake}

The Wenchuan earthquake with a magnitude of 8.0 occurred at 14:28:01 LT (06:28:01 UT) on 12 May 2008 in Sichuan province (Fig. 13 left). The epicenter was located at $31.021^{\circ} \mathrm{N} 103.367^{\circ} \mathrm{E}$ with a focal depth of $19 \mathrm{~km}$. This devastating earthquake was the object of many studies regarding the precursors because there are a lot of experiments to record various seismic parameters in China. In [1] they reviewed multi-satellite sensor and ground observatory data and they have reported anomalous changes in ground, meteorological and atmospheric parameters (air temperature and relative humidity) compared to other days. Electromagnetic precursors have been reviewed in $[61,62]$. They have shown that electromagnetic anomalies started 2.5 years earlier and were recorded until three days before the event. A more complete review of many different precursors has been made in [4] and their paper contains about 140 references related to various precursory phenomena observed before this earthquake. It concerns:

- Anomalies in deformation measurement which appear 3 days and 1 hour before,

- Anomalous variations in strain/stress measurements 48, 30, 8 hours and 37 minutes before,

- Possible structure variation five days before near the Longmenshan fault zone,

- Anomalous signals observed in broadband seismic and gravity records starting from about May 9-10, 2008,

- Geomagnetic anomalies 2 to 3 months before,

- Ionospheric anomalies starting from 13 to 2 days before,

- Geothermal and atmospheric anomalies, meteorological condition (10 months before), temperature variation since November 2007, large-scale satellite Thermal Infrared Anomaly (TIR) since March 2008, infrared radiation anomalies (two months before), and anomalies of outgoing long-wave radiation (fourty days before).

In a summary diagram, it has been shown [4] that the ionospheric anomalies are very short-term precursors with a peak appearance of five days before the earthquake. The number of reports about these ionospheric anomalies is also much more important than the other precursor reports. This could be due to the many different experiments used to study the ionosphere (iono-sounder, various GPS measurements giving access to the TEC, satellites which were able to survey several ionospheric parameters). Then, the next sections will briefly detail some events observed in the 

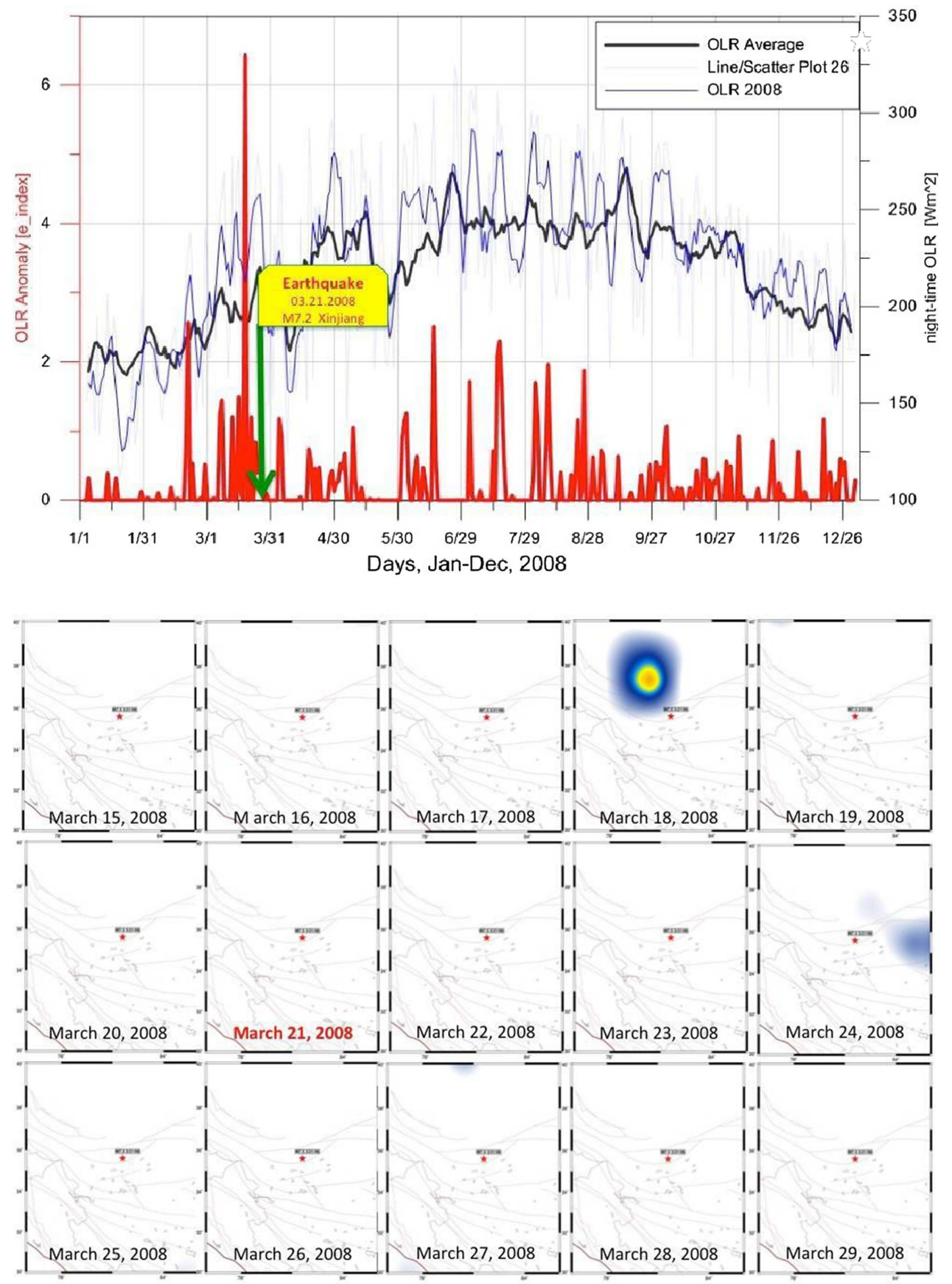

Fig. 10. Top: time series of daily night-time NOAA/AVHRR OLR anomalous values over the M7.2 earthquake of March 21, 2008 in Xinjiang Province for Jan-Dec 2008. OLR average values for 2008 (black), OLR daily values (blue) and anomalies for 2008 (red). The time of the earthquake is shown with a green arrow. Bottom: daily maps for March 15-29, 2008 representing the OLR anomalies spatial extent over the M7.2 earthquake of March 21, 2008 in Xinjiang Province epicentral area (with red star-epicenter, red solid lines-plate boundaries, brown lines-fault systems). 

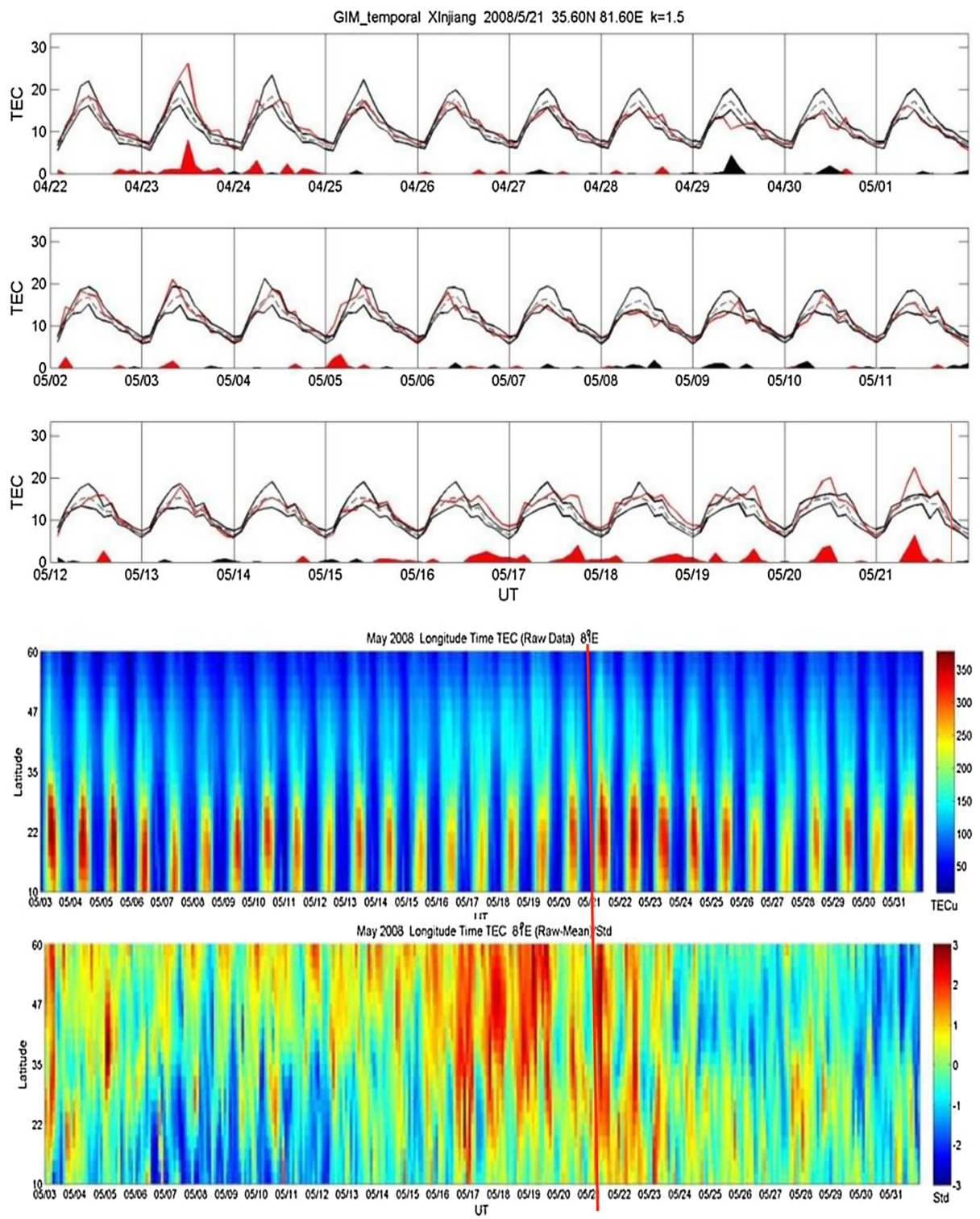

Fig. 11. Top: similar to Figures 2, and 5 but for GIM TEC data recorded during the time interval April 22-May 21 2008. The red line corresponds to the time occurrence of the earthquake. Bottom: presentation of GIM TEC data similar to Figures 3 bottom and 6 bottom but along the $81^{\circ} \mathrm{E}$ longitude and for the time interval May 3 - May 31, 2008. The red line corresponds to the earthquake day.

ionosphere by many different experiments which underline the appearance of perturbations five and three days before the earthquake.

\subsubsection{Atmospheric chemical potential}

The atmospheric chemical potential correction (Sect. 3.5) has been evaluated for the Wenchuan earthquake. The epicenter was along the Longmenshan fault where 


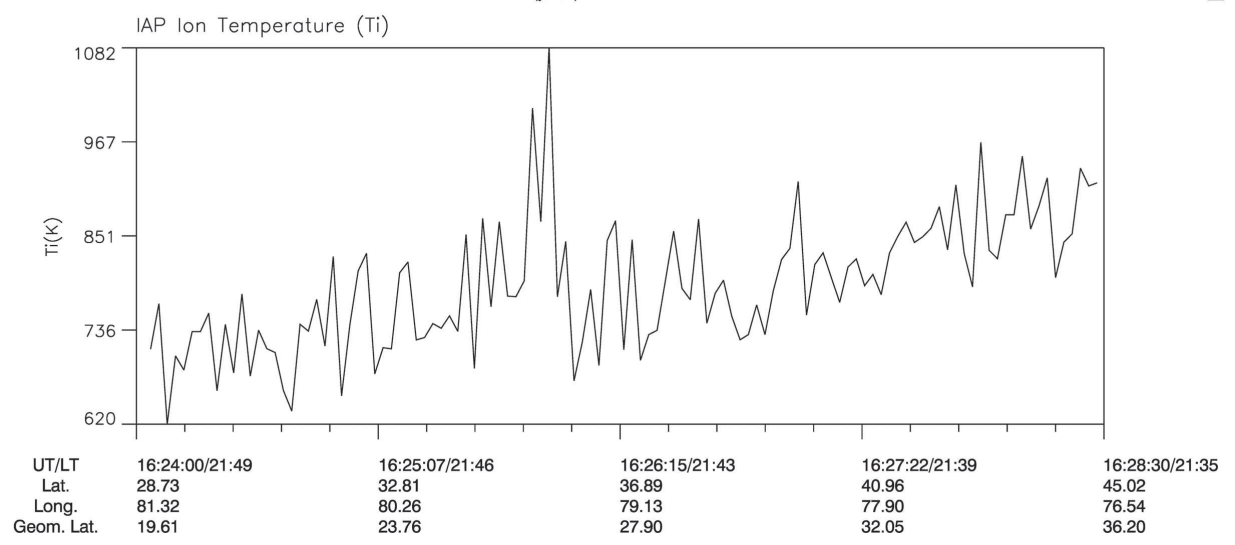

Fig. 12. Ion temperature recorded by DEMETER on March 12, 2008 between 16.24 .00 and 16.28.30 UT. The parameters below the plot are the geographic latitude and longitude, and the geomagnetic latitude. The closest approach to the earthquake epicenter is at 16.25.30 UT.
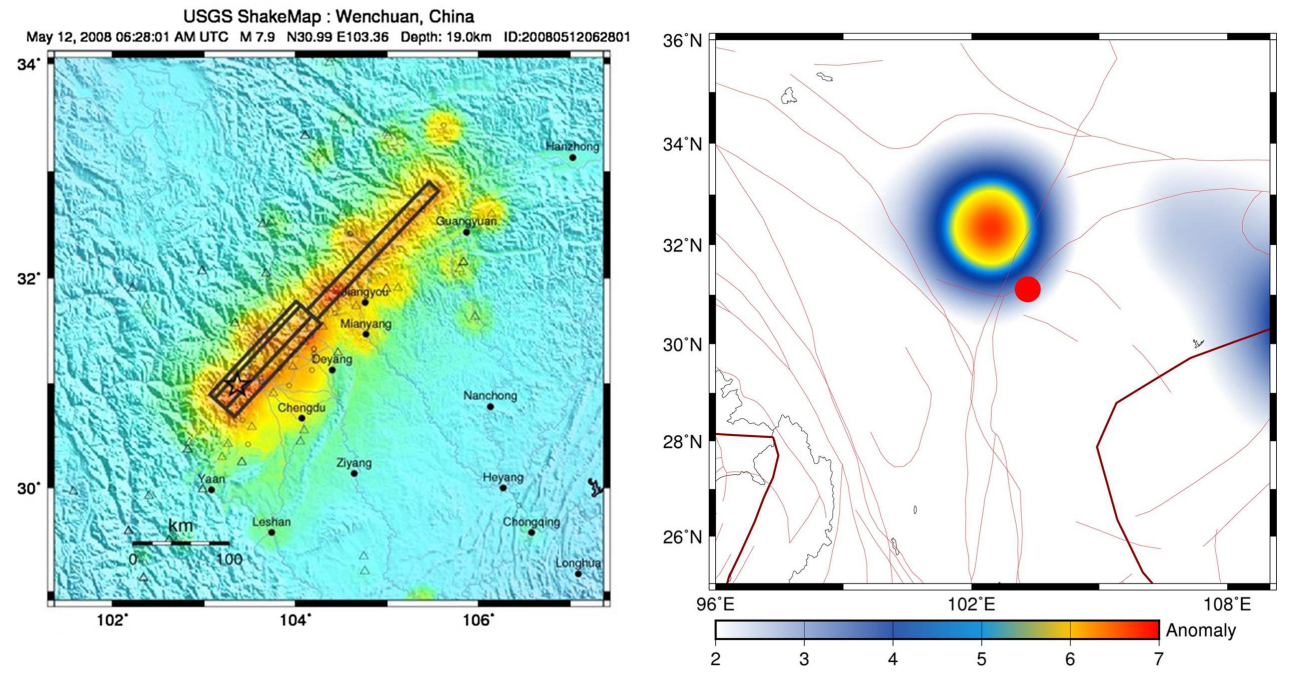

Fig. 13. Left: shake map showing the extent of the ruptured fault lines for the 2008 Wenchuan earthquake (USGS). Right: satellite OLR (NOAA15 data) of May 06, 2008.

the chemical potential correction distribution shows a minimum during several days before the earthquake. The temporal evolution of the chemical potential starting from 25 April 2008 is shown in Figure 14 left. In fact, the main activity is observed on both sides of the Longmenshan fault (Fig. 14 right where the spatial distribution of the chemical potential is shown on 01 and 11 May). So to observe this activity we have selected a point not exactly at the epicenter, but 1 degree to North and West from this epicenter, i.e. at $32^{\circ} \mathrm{N}, 102^{\circ} \mathrm{E}$.

\subsubsection{Outgoing Longwave Radiation variation and TIR anomalies}

Based on the OLR data of the geostationary satellite FY2-C and their variation characteristics, [63] has proposed a method for extracting earthquake TIR, namely, 

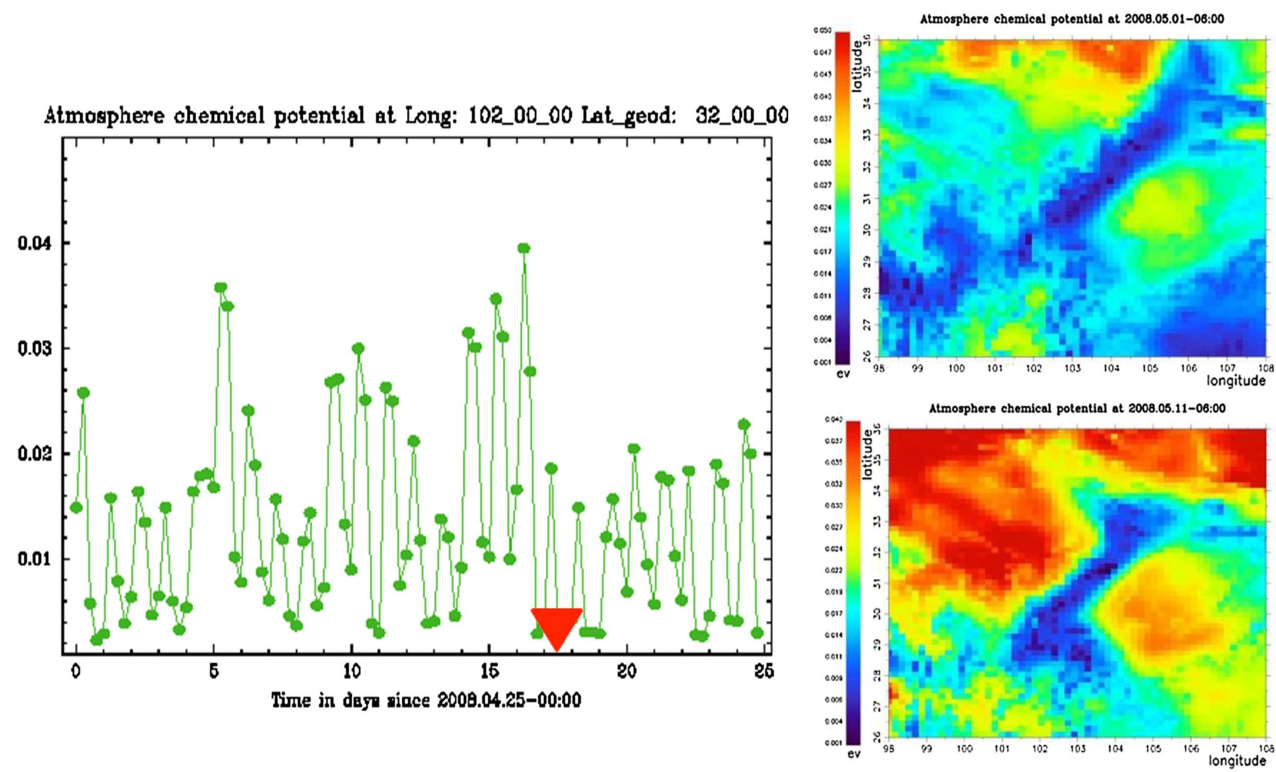

Fig. 14. Left: atmospheric chemical potential variations for the period 25 April - 19 May 2008 at the point $32^{\circ} \mathrm{N} 102^{\circ} \mathrm{E}$. The red triangle indicates the earthquake day. Right: chemical potential correction over of Wenchuan earthquake area on 01 May (top panel) and 11 May 2008 (bottom panel).

the relative variance rate of power spectrum estimation. The method was applied to analyze OLR for the Wenchuan earthquake and they show perturbed maps of TIRs on May 5 and 10. The changes in multiple parameters of the atmosphere have been analyzed [64], including OLR, surface latent heat flux (SLHF), air temperature (AT), air relative humidity (ARH), and air pressure (AP). OLR anomalies were first observed (thirteen days before). Next are the abnormal variations of AT, ARH, and $\mathrm{AP}$ which occurred almost at the same time (ten days before). It is very interesting to notice that the time of anomaly occurrence of these three parameters also corresponds to the time of the increase of radon. Lastly are the SLHF abnormal variations (one day before). Recently, the occurrence of atmospheric aerosols with MODIS data from both Terra and Aqua satellites has been investigated [65]. They have clearly shown an enhancement of the atmospheric aerosol optical depth associated with this earthquake by using MODIS data from both Terra and Aqua. It was along the Longmenshan faults seven days before the quake, i.e. one day and four days earlier than the reported negative and positive ionospheric disturbances, respectively. It is also interesting to note that it has been found in [66] significant displacement anomalies concomitant with ionospheric perturbations. They have shown variations of three displacement components at the LUZH station $\left(28.87^{\circ}, 105.41^{\circ}\right)$ on May 9 and even a vertical displacement of more than $300 \mathrm{~mm}$ at PIXI station $\left(30.91^{\circ}, 103.76^{\circ}\right)$, i.e. at $36 \mathrm{~km}$ from the epicenter, 1 hour before the earthquake.

The M7.9 event of May 12th shows OLR anomaly on May 6th (six days before the earthquake, see Fig. 15) that was building near to the epicenter area. The temporal variability (see the zoom in Fig. 13 right) map for the period of May 1-15, 2008 had confirmed that the maximum change in the OLR state over the epicenter area did occur on May 6th [47].

Concerning the TIR anomalies (Sect. 3.4), the Wenchuan area has been studied between April 1st, 2008 and May 31, 2008. Three SSTAs were identified and their 

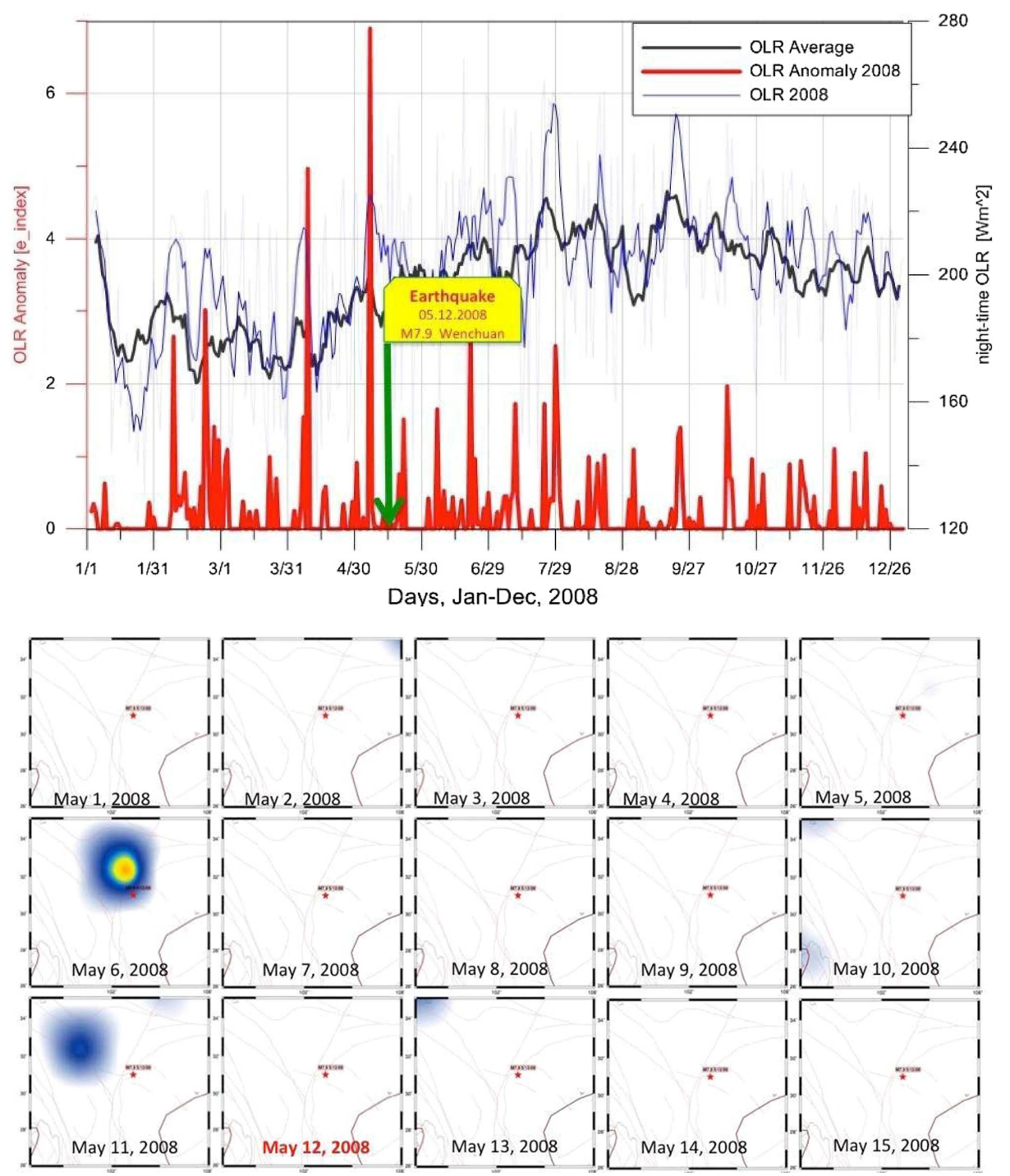

Fig. 15. Top: time series of daily night-time NOAA/AVHRR OLR anomalous values over epicenter area in Sichuan Province for Jan-Dec 2008. OLR average values for 2008 (black), OLR daily values (blue) and anomalies for 2008 (red). The time of the M7.9 earthquake is shown with a green arrow; Bottom: daily maps for May 1-15 2008 representing the OLR anomalies spatial extent in Sichuan province epicenter area (with red star - epicenter, red solid lines- plate boundaries, brown lines - fault systems). The earthquake occurred on May 12 th, 2008.

temporal relation with earthquakes with $M>5$ occurring within a distance $\mathrm{D}$ are described in Figure 16 (one SSTA per each row) and mapped in Figure 17. It should be noted that:

- SSTAs occur all within the space-time correlation window for the Wenchuan main shock,

- SSTAs occur all before the main shock in between one month (first appearance of SSTA 1 and 2) and two weeks (last appearance of SSTA 3). 


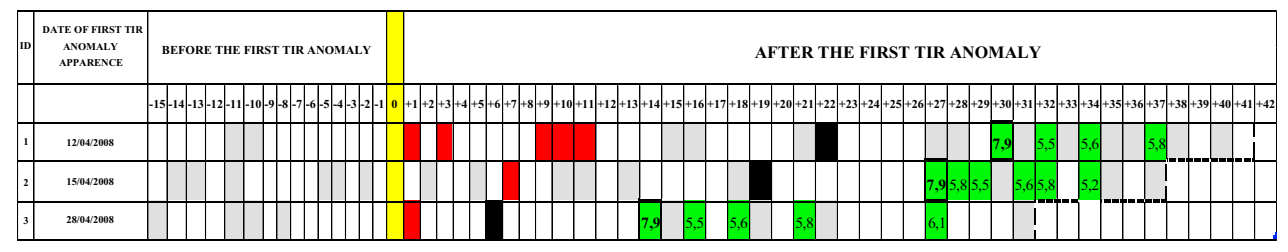

Fig. 16. Correlation analysis among SSTAs and Earthquake $(M>5)$ occurrence during the period April 1st-May 31st 2008. Each row corresponds to a succession of SSTAs occurring in a different area. Yellow cells correspond to the day (zero) of the first Significant TIR Anomalies (STA) each following persistence is depicted in red. Black and gray cells indicate, respectively, the absence of available satellite data and days with wide cloud coverage (not usable data) in the investigated area. Green cells with numbers indicate days of occurrence, and magnitude, of seismic events. For each SSTA the end of the time-correlation window (i.e. 30 days after last STA) is bounded by dashed black line.

\subsection{3 lonospheric variations of density (GPS/TEC)}

It has been shown [67] that the maximum ionospheric electron density in the F2 layer recorded by the Chinese iono-sounders over Wuhan $\left(30.5^{\circ} \mathrm{N}, 114.4^{\circ} \mathrm{E}\right)$ and Xiamen $\left(24.4^{\circ} \mathrm{N}, 123.9^{\circ} \mathrm{E}\right)$ presented an unusual large enhancement during the afternoonsunset sector on May 9. Using the FORMOSAT-3/COSMIC satellite constellation in [68], they were able to monitor the three-dimensional ionospheric structure with radio occultation observations. They have shown that near the epicenter the F2-peak height is about $25 \mathrm{~km}$ lower and the F2-peak electron density decreases around noon 5 days prior to the earthquake. In [69] they observed on May 9 at 15.00-17.00 LT a variation of the F2 layer using the ionospheric sounder of the Chongqing station $\left(29.50^{\circ} \mathrm{N}\right.$, $\left.106.40^{\circ} \mathrm{E}\right)$. Using the LUZH GPS station $\left(28.87^{\circ}, 105.41^{\circ}\right)$ close to the epicenter, it has been observed in [70] that VTECs were lower in the period of 07:00-09:00 UT on May 6, and larger in the periods of 04:00-06:00 UT on May 3 and 08:00-11:00 UT on May 9, showing negative and positive anomalies, respectively. With a statistical analysis of several GPS stations close to the epicenter, it has been confirmed [71] that TEC enhancements occurred on May 3 and 9. One also reports a change of the EIA and an anomalous enhancement in TEC (100\% increase on the 15-day median) during the afternoon-evening sector (13:00-20:00 LT, i.e. 05:00-12:00 UT) on 9 May 2008 [72]. Global Ionosphere Maps (GIMs) presented in [73] indicate that TEC anomalies occurring locally are stronger than those occurring globally at 15:00-17:00 Local Time (LT) on 29 April, 16:00 and 21:00 LT on 6 May and 14:00 and 19:00-21:00 LT on 7 May. TEC variations have been studied in [74] with GIM (Global Ionospheric Map) data provided by the NASA Jet Propulsion Laboratory (JPL). They have an unusual decrease of electron density $(-13 \%)$ at $\sim 22: 30 \mathrm{LT}$, three days before the earthquake and an increase of the order of $39 \%$, from the normal state nine days before the earthquake. The analysis of a dual- frequency global positioning system (GPS) receiving set-up at Guwahati $\left(26^{\circ} 10 \mathrm{~N}, 91^{\circ} 45 \mathrm{E}\right)$ made in [75] with a large number of satellites indicates variations of TEC $2-3$ days prior to the earthquake, i.e. on 9 and 10 May. To calculate TEC, [76] used the global IONEX TEC maps, and the reconstructed vertical profiles of electron density according to the network of GPS receivers in the earthquake region. They have shown variations of the equatorial anomaly and they have attributed these variations to the appearance of anomalous zonal and meridional electric fields generated before this earthquake. From TEC maps, it has been found in [77] that in the afternoon (16:00-18:00 LT) on May 9, 2008 , i.e. three days before the earthquake, a distinct TEC enhancement appearing in the east-south direction of Wenchuan, and another enhancement in the conjugate 

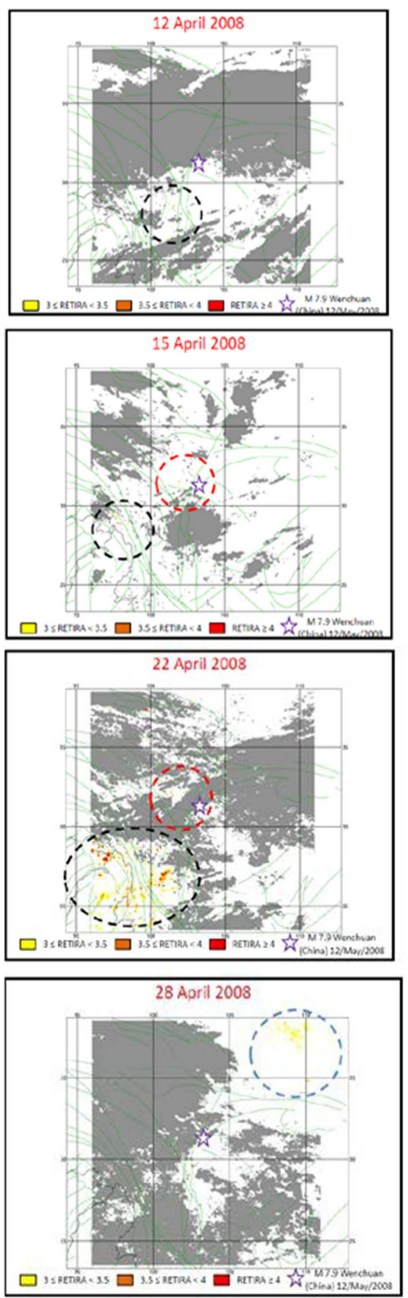
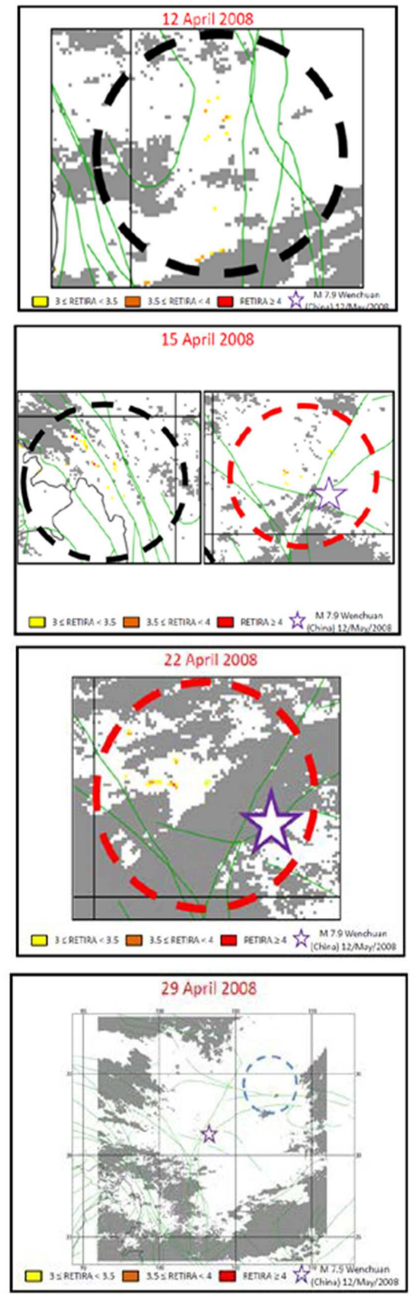
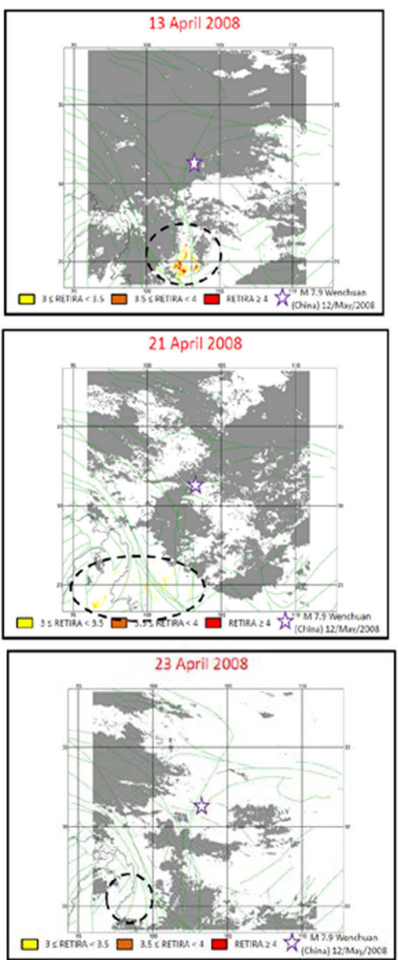

Fig. 17. Space-time distribution of the 3 observed SSTAs. Significant Thermal Anomalies (STA) are differently colored depending on their relative intensities (in terms of number of $\sigma$ over the expected value, see text). Clouds (no usable data) are grey colored. Dashed circles delimit the SSTAs' affected areas: Black $=$ SSTAs 1 , Red $=$ SSTAs 2, Blue $=$ SSTAs 3 . The star indicates the epicenter of Wenchuan EQ. Some SSTAs occurring on April 12, 15 and 22 are zoomed and reproduced close to the corresponding maps.

region in the Southern Hemisphere. In [78] they calculated the daily averaged values of $\mathrm{Ni}$ (ion density) recorded by the satellite DEMETER during the local nighttime from May 1 to 12 in the latitudinal interval of $20^{\circ} \mathrm{N}-40^{\circ} \mathrm{N}$ within $2000 \mathrm{~km}$ of the epicenter, and they found the lowest value three days before the Wenchuan earthquake. In [79] they analyzed also the DEMETER data and found that (i) electron density, electron temperature and oxygen ion density changed sharply (greater than 20\%) near the epicenter four and five days prior to the shock, (ii) increased electromagnetic emissions were registered when the satellite passed the epicenter three and seven days before the shock (i.e. on May 5 and 9). Using the density measured by DEMETER, it has been found in $[80,81]$ an anomalous increase centered close to the epicenter by comparison between values recorded just before the quake and values recorded later on. 

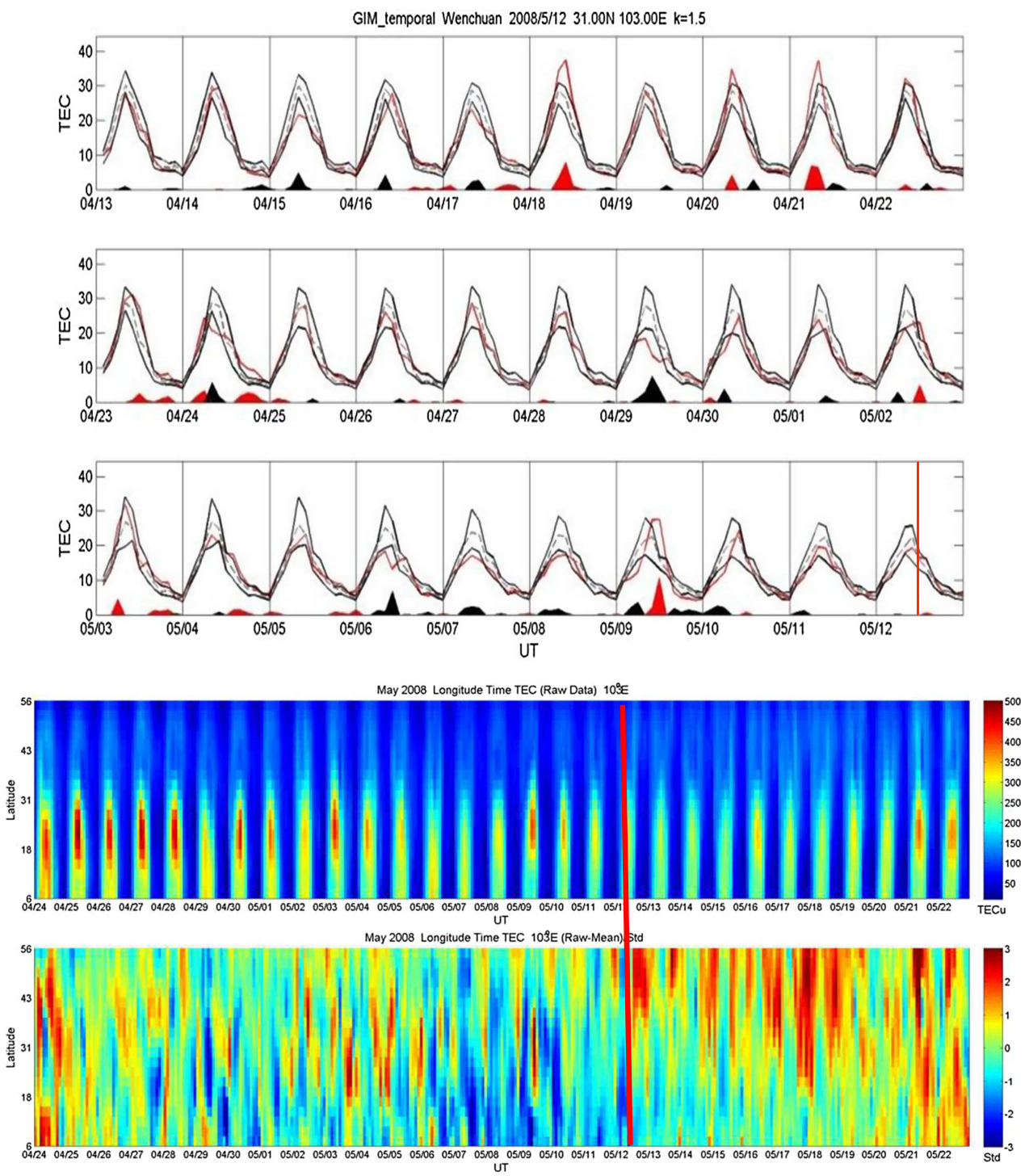

Fig. 18. Top: similar to Figures 2, 5 and 11 top but for GIM TEC data recorded during the time interval April 13-May 12 2008. The red line indicates the earthquake day. Bottom: presentation of GIM TEC data similar to Figures 3 bottom, 6 bottom and 11 bottom but along the $103^{\circ} \mathrm{E}$ longitude and for the time interval April 24 - May 22, 2008. The red line indicates the earthquake day.

The GIM shows in Figure 18 top that the TEC over the epicenter significantly decreases on April 29, and on May 6, i.e. 13 and 6 days before the earthquake. This well agrees with the results reported in $[55,73,100]$. One can notice that there is a positive anomaly appearing in the afternoon of May 9. The TEC over the epicenter simply and slightly decreases during the period May 1 - May 5. In Figure 18 bottom, the GIM TEC along the $103^{\circ} \mathrm{E}$ longitude is extracted during the period April $24-$ May 22, 2008. In this case, the magnetic equator should be around $3^{\circ} \mathrm{N}$. The top and lower panels are the GIM TEC and associated variation normalized by the standard deviation, respectively. The lower panel reveals that the TEC $20^{\circ} \mathrm{N}-40^{\circ} \mathrm{N}$ within 
$2000 \mathrm{~km}$ of the epicenter significantly decreases $(2 \sigma)$ during the period May 1 - May 12. This generally agrees with the DEMETER results reported in [78].

A complete evolution of the position of the anomaly is shown in Figure 19 which represents the differential maps of GIM TEC. It can be seen that the anomaly is well located close to the epicenter. Except at the beginning of the investigated period one also see that the magnetic activity is quiet (right bottom panel of Fig. 19) and then the observed anomalies cannot be attributed to a perturbation due to the solar activity. One can also observe the large perturbation occurring one hour and half after the earthquake on May 12 due to the shock and the tsunami $[82,83]$.

\subsection{4 lonospheric variations of the electron density (DEMETER/EIA)}

In the past, several statistical analyses with the electron density recorded by DEMETER have shown that there is a variation of this parameter between a few hours and a few days before earthquakes [80,84].

For this event an additional analysis of the DEMETER density has been done. The DEMETER data have been checked during one month and half, one month before the shock and fifteen days after. DEMETER is only two times per day above a given region (once during daytime - 10 LT and once during night time - 22 LT). Then the data have been studied in a rectangle centered on the epicenter (longitude range between $93^{\circ}$ and $113^{\circ}$, latitude range between $22^{\circ}$ and $40^{\circ}$ ). This longitude range has been selected in order to have at least one orbit per day in the seismic region. Each orbit track is therefore more or less close to the epicentre. For each orbit, the electron density data measured by the Langmuir probe have been averaged according to the latitude. Then all daily values which are obtained at $10 \mathrm{LT}$ are displayed in Figure 20. The red line represents the average value of these densities during the complete time interval and the dashed lines correspond to the variance. One can see a decrease of the density $2-3$ days before the earthquake during daytime as it was reported in the ionospheric studies mentioned above. The magnetic activity is quiet during the period of Figure 20 except at the beginning, on April 23, where the Dst index is equal to $-46 \mathrm{nT}$. Then, the large increase of the density at this time cannot be attributed to the seismic activity.

In [85] they have compared data from GPS receivers, the DEMETER satellite, and the Advanced Very High Resolution Radiometer (AVHRR) onboard NOAA satellite. They found that GPS total electron content (TEC) above the epicenter continuously decreased in the afternoon periods from 6 to 10 May but increased in the afternoon of 9 May. Change between positive and negative anomalies can be explained when we consider the Global Electric Circuit (GEC) which exists between the atmosphere and the ionosphere. At the boundary layer, it depends on whether the densities of light ions are larger than the density of heavy ions or not [16]. The density recorded by DEMETER also decreased from 6 to 10 May, mainly in the south of the epicenter. The brightness temperature from NOAA/AVHRR data is enhanced on the northwest side of the epicenter on 7 May, while ion temperature from DEMETER data increased on 9 May. The flux of energetic particle between 100 and $600 \mathrm{keV}$ is enhanced on 6 May. They claim that the perturbations of these parameters before the Wenchuan earthquake may be related to the changes of vertical electric field in the atmosphere and ionosphere.

Using a normalized electron density of DEMETER, it has been shown that, during day time, there is EIA enhancements near the epicenter longitude that began approximately 1 month before the earthquake and reached its maximum with an exceptionally large strength index eight days prior to the main shock [36]. 

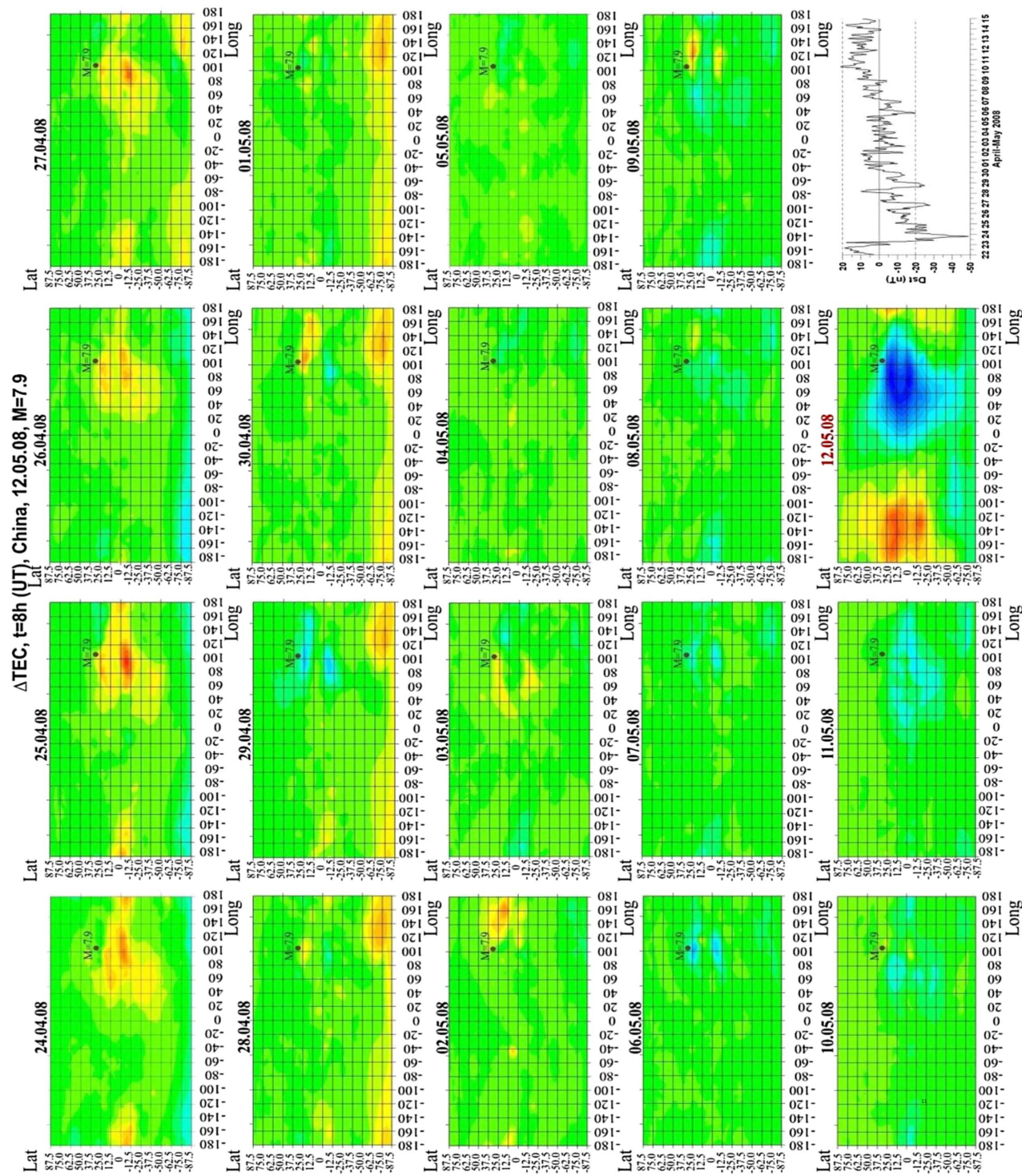

Fig. 19. Differential maps of GIM TEC for the period 24 April - 12 May 2005. Each panel corresponds to data recorded during a different day at $08 \mathrm{UT}$. The right bottom panel shows the evolution of the Dst index during the same period.

\subsection{5 lonospheric perturbations of waves}

The analysis of the waveform of the electric field measured by DEMETER with Fourier, wavelet and bi-spectral methods has shown the presence of strong emissions in the ELF frequency range in the ionosphere six and three days before the earthquake [86]. In [87], a comparison has been made between electric field measured with groundbased stations located not far from the epicenter (less than $410 \mathrm{~km}$ ) and the ELF magnetic field recorded by DEMETER. They have shown for the first time that there is an obvious seismo-electromagnetic relation between the ground and the ionosphere 


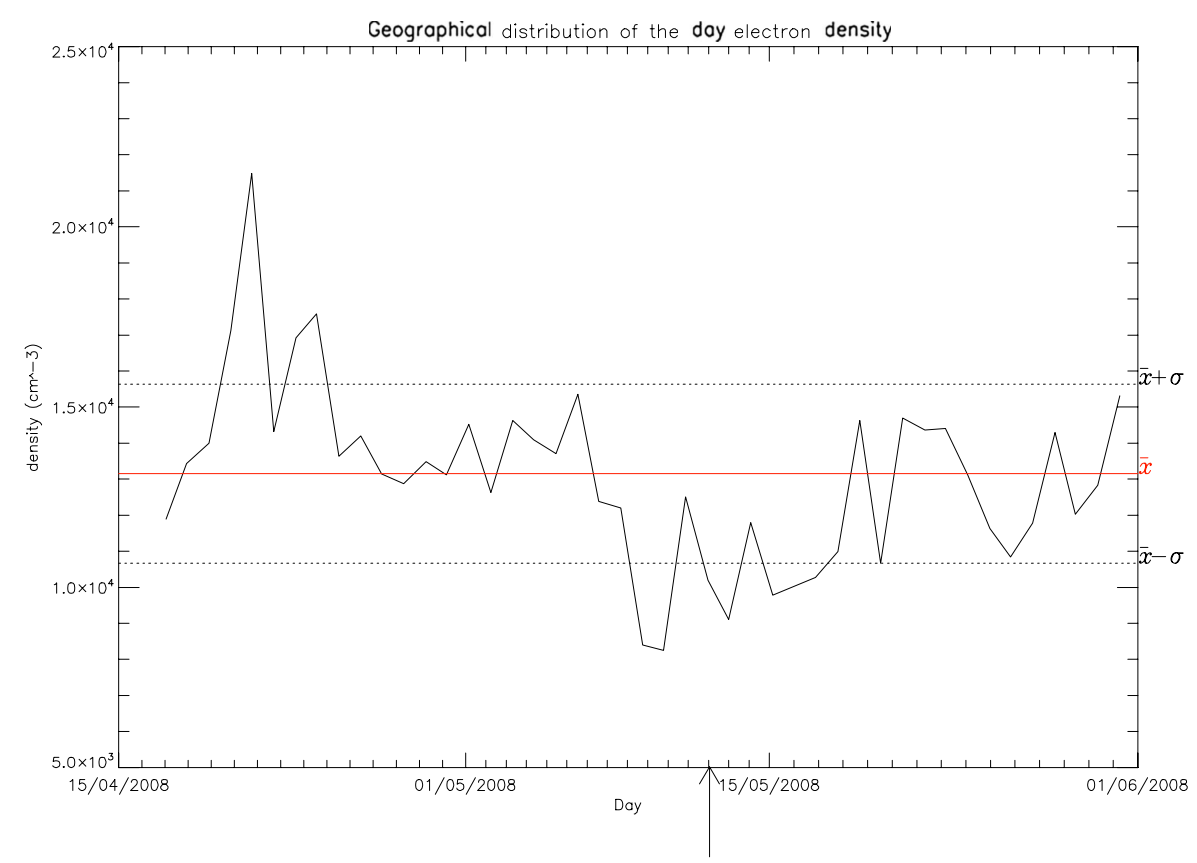

Fig. 20. Day time variation of the electron density in a rectangle around the epicenter (longitude range between $93^{\circ}$ and $113^{\circ}$, latitude range between $22^{\circ}$ and $40^{\circ}$ ) as function of days. The arrow indicates the earthquake day. The red line corresponds to the average value over the considered period and the dotted lines are related to the standard deviation.

because increases of the signals are observed at the same time (starting two weeks before the quake) on ground and on the satellite. It has been shown [88] that during night the ULF noise exhibits large changes relative to the background levels at the time that DEMETER flies over the region of the epicenter, around the end of March, mid- to late-April, mid-May, and early and mid-June.

In [89] they have checked the DEMETER electric field data in the ULF range and a comparison was done with data recorded by ground-based stations. They have shown an increase in the electric field amplitude (from one to two orders of magnitude) starting from April 27, 2008 to the time of the earthquake. In [62] they have also studied the ground-based and satellite DC-ULF electric field data around Wenchuan. They have shown that the ground and space electric field anomalies have similar time and space behaviors. The analysis of long time series illustrates that the abnormal geo-electric field started in March 2008. Recently, in [90] they used the ULF data from two Chinese stations Chengdu and Xichang at $80 \mathrm{~km}$ and $300 \mathrm{~km}$ from the epicenter, respectively. They have found a depression of the ULF horizontal magnetic field at Chengdu a few days before the earthquake during the local night time period. They suggested that it was due to a perturbation of the lower ionosphere. The same data were differently processed in [91] using a natural time analysis on various ULF parameters. They have shown critical features in the time period of 17-27 April, i.e. about one month to two weeks before the earthquake.

\section{Discussion and conclusions}

Reviews of past studies together with new investigations of atmospheric and ionospheric parameters have been done for several powerful earthquakes. During the week 
Table 2. Summary of ACP, OLR/TIR, EIA, dTEC and DEMETER anomalies observed in relation to the studied earthquakes.

\begin{tabular}{|c|c|c|c|c|c|c|}
\hline \multirow[t]{4}{*}{ \# } & $\begin{array}{l}\Rightarrow \mathrm{EQ} \\
\text { events }\end{array}$ & $\begin{array}{l}\text { ACP } \\
\text { Anomalies }\end{array}$ & $\begin{array}{l}\text { OLR/TIR } \\
\text { Anomalies }\end{array}$ & $\begin{array}{l}\text { EIA } \\
\text { Anomalies }\end{array}$ & $\begin{array}{l}\text { GPS/dTEC } \\
\text { Anomalies }\end{array}$ & $\begin{array}{l}\text { DEMETER } \\
\text { Anomalies }\end{array}$ \\
\hline & & Date & Date & Date & Date & Date \\
\hline & & Value & Value & Value & Value & Value \\
\hline & & Lag (days) & Lag (days) & Lag (days) & Lag (days) & Lag (days) \\
\hline \multirow[t]{3}{*}{1} & M8.6 Nias, Sum & na & 03.15 & 08.23 & $03.22-23$ & 08.28 \\
\hline & 28 March 2005 & & $8 \mathrm{Wm}^{-2}$ & & $60 \%$ & \\
\hline & & & -13 & -5 & -5 & $-20 \mathrm{~min}$ \\
\hline \multirow[t]{3}{*}{2} & M8.5 Sumatra, & na & 09.02 & 09.03 & 09.09 & 09.10 \\
\hline & 12 Sept 2007 & & $8 \mathrm{Wm}^{-2}$ & & $70 \%$ & \\
\hline & & & -10 & -10 & -3 & -2 \\
\hline \multirow[t]{3}{*}{3} & M7.2 Yutian, Xinjiang- & 03.17 & 03.18 & na & 03.19 & 03.12 \\
\hline & Xizang China, & $0.06 \mathrm{eV}$ & $7 \mathrm{Wm}^{-2}$ & & $20 \%$ & \\
\hline & 20 March 2008 & -5 & -3 & & -2 & -8 \\
\hline \multirow[t]{3}{*}{4} & M8.0 Wenchuan, Sichuan, & $05.09-05.06$ & 05.06 & 05.04 & 05.09 & $05.08-05.09$ \\
\hline & China & $0.04 \mathrm{eV}$ & $7 \mathrm{Wm}^{-2}$ & & $40 \%$ & \\
\hline & 12 May 2008 & -6 to -3 & -6 & -8 & -3 & -3 to -2 \\
\hline
\end{tabular}

preceding the earthquakes, all these parameters show clear disturbances that can be considered as short-term precursors (summary in Table 2). Two important points must be underlined: (i) these variations are expected by the proposed LAIC concept, and (ii) there is a large similarity of these variations for the different earthquakes presented in this paper. For example, our analysis of OLR from satellite during the M7.2 earthquake of March 21, 2008 in Xinjiang province and the M7.9 earthquake of May 12, 2008 in Sichuan province demonstrated the presence and re-occurrences of related variations of this parameter implying its connection with the earthquake preparation process. The same phenomena were revealed for the ionospheric perturbations of the local electron density measured from ground or by satellite, and of the global TEC measured prior to the different earthquakes. The influence of the global electric circuit between the Earth's surface and the bottom of the ionosphere has been confirmed in [92] who have shown similarities between electric field simultaneously recorded onboard DEMETER and on ground.

These results can be explained by the LAIC concept, which suggests the existence of physical links between the different atmospheric variations and tectonic activity $[1,93]$. The triggering process is the air ionization produced by increased emanation of radon from the Earth's crust in the vicinity of active tectonic faults [17]. Our findings provided evidence of the thermal build up in the form of increasing mean air temperature in the atmosphere, and change of the relative humidity because the produced ions act as the nuclei for water vapor condensation. During the condensation a large amount of latent heat is released, which leads to the air temperature changes. The measurements show that infrared temperature increases by several degrees for different large earthquakes. Independently of the results shown here concerning the atmospheric chemical potential (Figs. 9 and 14), a clear enhancement of the atmospheric aerosols seven days before the Wenchuan earthquake has been shown [65].

This is not specific for the earthquakes under studies because recently [94] and [95] have also detected variations of aerosols before the M8.8 Chile earthquake in 2010, and the M7.9 Nepal earthquake in 2015, respectively. An increased density of the charged aerosols in the warm humid air over the tectonic fault leads to the intensive vertical electric currents generation $[12,96]$, which results in the local disturbances of the electric field in the ionosphere and create relative TEC disturbances via the electromagnetic plasma drift $[10,97]$. 
This does not rule out the possibility that under specific conditions other mechanisms can trigger such perturbations as it is explained at the end of Section 2 .

Finally, the coupling interaction phenomena related to earthquakes was demonstrated in this work by the analysis of atmospheric and ionospheric observations associated with the M8.6 of March 28, 2005 and the M8.5 September 12, 2007 in Sumatra, the M7.9 May 12, 2008 in Wenchuan, China and the M7.2 March 2008 in the Xinjiang-Xizang, China, earthquakes. The synergy of related variations of these parameters suggests that they follow a general temporal-spatial evolution pattern proposed by the LAIC concept, which has been seen in other large earthquakes worldwide [101].

The authors thanks the NOAA's Climate Prediction Center for OLR data. The satellite DEMETER was operated between 2004 and 2010 by the French Centre National d'Etudes Spatiales. The authors thank ISSI (Beijing) for their support of the team "Validation of Lithosphere-Atmosphere-Ionosphere-Magnetosphere Coupling (LAIMC) as a concept for geospheres interaction by utilizing space-borne multi-instrument observations". The DEMETER data are available at https://cdpp-archive.cnes.fr/ while the global ionosphere maps (GIM) are at ftp://cddisa.gsfc.nasa.gov/pub/gps/products/ionex. OLR data location of NCAR and NOAA are at ftp ftp.cpc.ncep.noaa.gov (cd precip/noaa*).

Publisher's Note The EPJ Publishers remain neutral with regard to jurisdictional claims in published maps and institutional affiliations.

\section{References}

1. S. Pulinets, D. Ouzounov, J. Asian Earth Sci. 41, 371 (2011)

2. J. Milne, Trans. Seismol. Soc. Jpn. 15, 135 (1890)

3. M. Hayakawa, The frontier of earthquake prediction studies (Nihon-SenmontoshoShuppan, 2012)

4. T. Ma, Z. Wu, Int. J. Geophys. 2012, 583097 (2012)

5. S.A. Pulinets, D. Ouzounov, A.V. Karelin, K.A. Boyarchuk, L.A. Pokhmelnykh, Phys. Chem. Earth 31, 143 (2006)

6. S.A. Pulinets, D.P. Ouzounov, A.V. Karelin, D.V. Davidenko, Geomagn. Aeron. 55, $521(2015)$

7. S. Pulinets, D. Ouzounov, A. Karelin, D. Davidenko, Pre-earthquake processes: a multi-disciplinary approach to earthquake prediction studies, in Geophysical Monograph Series, edited by D. Ouzounov, S. Pulinets, K. Hattori, P. Taylor, (AGU and John Wiley \& Sons Inc., 2018), Vol. 234, p. 79

8. F.T. Freund, I.G. Kulahci, G. Cyr, J.L. Ling, M. Winnick, J. Tregloan-Reed, M.M. Freund, J. Atmos. Sol.-Terr. Phys. 71, 1824 (2009)

9. R.G. Harrison, K.L. Aplin, M.J. Rycroft, J. Atmos. Sol.-Terr. Phys. 72, 376 (2010)

10. M.I. Karpov, A.A. Namgaladze, O.V. Zolotov, Russ. J. Phys. Chem. B 7, 594 (2013)

11. C.L. Kuo, L.C. Lee, J.D. Huba, J. Geophys. Res. 119, 3189 (2014)

12. V.M. Sorokin, Yu.Ya. Ruzhin, Geomagn. Aeron. 55, 626 (2015)

13. V. Tramutoli, R. Corrado, C. Filizzola, N. Genzano, M. Lisi, N. Pergola, Boll. Geof. Teor. Appl. 56, 167 (2015)

14. V.P. Kim, V.V. Hegai, J.Y. Liu, K. Ryu, J.K. Chung, J. K., J. Astron. Space Sci. 34, 251 (2017)

15. S. Pulinets, Int. J. Geophys. 2012, 131842 (2012)

16. S. Pulinets, D. Davidenko, Adv. Space Res. 53, 709 (2014)

17. V.V. Surkov, Ann. Geophys. 58, A0554 (2015)

18. F. Freund, Acta Geophys. 58, 719 (2010)

19. F. Freund, Acta Geophys. 61, 775 (2013)

20. F.T. Freund, M.M. Freund, J. Asian Earth Sci. 114, 373 (2015) 
21. J. Scoville, J. Sornette, F.T. Freund, J. Asian Earth Sci. 114, 338 (2015)

22. J.Y. Liu, C. K. Chao, Terr. Atmos. Ocean. Sci. 28, 117 (2017)

23. M. Parrot, Earthq. Sci. 24, 513 (2011)

24. M. Li, M. Parrot, J. Geophys. Res. Space Phys. 118, 3731 (2013)

25. D. Ouzounov, S. Pulinets, K. Hattori, P. Taylor, Pre-Earthquake Processes: A Multidisciplinary Approach to Earthquake Prediction Studies, in Geophysical Monograph Series (AGU and John Wiley \& Sons Inc., 2018), Vol. 234

26. M. Parrot, Planet. Space Sci. 54, 411 (2006)

27. S. Namba, K.-I. Maeda, Radio Wave Propagation (Corona, Tokyo, 1939)

28. E.V. Appleton, Nature 157, 691 (1946)

29. R.A. Duncan, J. At. Terr. Phys. 18, 89 (1960)

30. W.B. Hanson, R.J. Moffett, J. Geophys. Res. 71, 5559 (1966)

31. D.N. Anderson, Planet. Space Sci. 21, 409 (1973)

32. N. Balan, G.J. Bailey, J. Geophys. Res. 100, 21,421 (1995)

33. H. Rishbeth, Ann. Geophys. 18, 730 (2000)

34. C.H. Lin, J.Y. Liu, T.W. Fang, P.Y. Chang, H.F. Tsai, C.H. Chen, C.C. Hsiao, Geophys. Res. Lett. 34, L19101 (2007)

35. K. Ryu, E. Lee, J.S. Chae, M. Parrot, K.-I. Oyama, J. Geophys. Res. Space Phys. 119, $4767(2014)$

36. K. Ryu, M. Parrot, S.G. Kim, K.S. Jeong, J.S. Chae, S. Pulinets, K.-I. Oyama, J. Geophys. Res. Space Phys. 119, 305 (2014)

37. S. Klotz, N. L. Johnson, Encyclopedia of statistical sciences (John Wiley and Sons, 1983)

38. J.Y. Liu, H. Le, Y.I. Chen, C.H. Chen, L. Liu, W. Wan, Y.Z. Su, Y.Y. Sun, C.H. Lin, M.Q. Chen, J. Geophys. Res. Space Phys. 116, A04302 (2011)

39. V. Tramutoli, G. Di Bello, N. Pergola, S. Piscitelli, Ann. Geophys. 44, 295 (2001)

40. V. Tramutoli, V. Cuomo, C. Filizzola, N. Pergola, C. Pietrapertosa, Remote Sens. Environ. 96, 409 (2005)

41. A. Eleftheriou, C. Filizzola, N. Genzano, T. Lacava, M. Lisi, R. Paciello, N. Pergola, F. Vallianatos, V. Tramutoli, Pure Appl. Geophys. 173, 285 (2016)

42. N. Genzano, C. Filizzola, R. Paciello, N. Pergola, V. Tramutoli, J. Asian Earth Sci. 114, $289(2015)$

43. G. Ohring, A. Gruber, Adv. Geophys. 25, 237 (1982)

44. A. Gruber, A.F. Krueger, Bull. Amer. Meteor. Soc. 65, 958 (1984)

45. A. Mehta, J. Susskind, J. Geophys. Res. 104, 12,193 (1999)

46. D. Ouzounov D. Liu, C. Kang, G. Cervone, M. Kafatos, P. Taylor, Tectonophysics 431, $211(2007)$

47. D. Ouzounov, S. Habib, S. Ambrose, in Risk Wise (International Disaster and Risk Conference (IDRC) Davos, Switzerland, Tudor Rose, 2008), p. 162

48. P. Xiong, X.H. Shen, Y.X. Bi, C.L. Kang, L.Z. Chen, F. Jing, Y. Chen, Nat. Hazards Earth Syst. Sci. 10, 2169 (2010)

49. L.F. Khilyuk, G.V. Chillingar, J.O. Jr Robertson, B. Endres, Gas migration. Events preceding earthquakes (Gulf Publishing Company, Houston, Texas, 2000)

50. W.C. Burnett, G. Kim, D. Lane-Smith, J. Radioanal. Nucl. Chem. 249, 167 (2001)

51. T.-H. Peng, W.S. Broecker, G.G. Mathieu, Y.-H. Li, J. Geophys. Res. 84, 2471 (1979)

52. A. Tronin, Remote Sens. 2, 124 (2010)

53. X. Zhang, J. Liu, X. Shen, M. Parrot, J.-D. Qian, X.-Y. Ouyang, S.-F. Zhao, J.-P. Huang, Chinese J. Geophys. 53, 567 (2010)

54. A.M. Hasbi, M.A. Mohd Ali, N. Misran, Nat. Hazards Earth Syst. Sci. 11, 597 (2011)

55. J.Y. Liu, Y.I. Chen, C.H. Chen, C.Y. Liu, C. Y. Chen, M. Nishihashi, J.Z. Li, Y.Q. Xia, K.I. Oyama, K. Hattori, C.H. Lin, J. Geophys. Res. Space Phys. 114, A04320 (2009)

56. X. Zhang, C. Fidani, J. Huang, X. Shen, Z. Zeren, J. Qian, Nat. Hazards Earth Syst. Sci. 13, 197 (2013)

57. X. Zhang, X. Shen, M. Parrot, Z. Zeren, X. Ouyang, J. Liu, J. Qian, S. Zhao, Y. Miao, Nat. Hazards Earth Syst. Sci. 12, 75 (2012) 
58. S. Hirooka, K. Hattori, M. Nishihashi, T. Takeda, Nat. Hazards Earth Syst. Sci. 11, $2341(2011)$

59. M.N. Cahyadi, K. Heki, J. Geophys. Res. Space Phys. 118, 1777 (2013)

60. R.P. Singh, W. Mehdi, R. Gautam, J.S. Kumar, J. Zlotnicki, M. Kafatos, Int. J. Remote Sens. 31, 3341 (2010)

61. X. Zhang, X. Shen, Int. J. Geophys. 2011, 904132 (2011)

62. X. Zhang, H. Chen, J. Liu, X. Shen, Y. Miao, X. Du, J. Qian, Adv. Space Res. 50, 85 (2012)

63. X. Guo, Y.-S. Zhang, M.-J. Zhong, W.-R. Shen, C.-X. Wei, Chinese J. Geophys. 53, $980(2010)$

64. F. Jing, X.H. Shen, C.L. Kang, P. Xiong, Nat. Hazards Earth Syst. Sci. 13, 27 (2013)

65. K. Qin, L.X. Wu, S. Zheng, Y. Bai, X. Lv, Adv. Space Res. 54, 1029 (2014)

66. G. Gu, G. Meng, Y. Fang, Acta Seismol. Sin. 33, 319 (2011)

67. B. Zhao, M. Wang, T. Yu, W. Wan, J. Lei, L. Liu, B. Ning, J. Geophys. Res. 113, A11304 (2008)

68. C.-C. Hsiao, J.Y. Liu, K.-I. Oyama, N.L. Yen, Y.A. Liou, S.S. Chen, J.J. Miau, GPS Solut. 14, $83(2010)$

69. T. Xu, Y. Hu, J. Wu, Z. Wu, C. Li, Z. Xu, Y. Suo, Adv. Space Res. 47, 1001 (2011)

70. Z. Yiyan, W. Yun, Q. Xuejun, Z. Xunxie, J. Atmos. Terr. Phys. 71, 959 (2009)

71. J. Li, G. Meng, M. Wang, H. Liao, X. Shen, Earthq. Sci. 22, 545 (2009)

72. B. Zhao, M. Wang, T. Yu, G. Xu, W. Wan, L. Liu, Int. J. Remote Sens. 31, 3545 (2010)

73. H.K. Jhuang, Y.Y. Ho, Y. Kakinami, J.Y. Liu, K.I. Oyama, M. Parrot, K. Hattori, M. Nishihashi, D. Zhang, Int. J. Remote Sens. 31, 3579 (2010)

74. M. Akhoondzadeh, M. Parrot, M.R. Saradjian, Nat. Hazards Earth Syst. Sci. 10, 7 (2010)

75. M. Devi, A.K. Barbara, A.H. Depueva, Y.Y. Ruzhin, V. Depuev, Int. J. Remote Sens. 31, 3589 (2010)

76. S.A. Pulinets, V.G. Bondur, M.N. Tsidilina, M.V. Gaponova, Geomagn. Aeron. 50, $231(2010)$

77. M.V. Klimenko, V.V. Klimenko, I.E. Zakharenkova, S.A. Pulinets, B. Zhao, M.N. Tsidilina, Adv. Space Res. 48, 488 (2011)

78. X. Zhang, X. Shen, J. Liu, X. Ouyang, J. Qian, S. Zhao, Nat. Hazards Earth Syst. Sci. 9, $1259(2009)$

79. Z.C. Zeng, B. Zhang, G.Y. Fang, D.F. Wang, H.J. Yin, Chinese J. Geophys. 52, 13 (2009)

80. Y. He, D. Yang, J. Qian, M. Parrot, Nat. Hazards Earth Syst. Sci. 11, 2173 (2011)

81. Y. He, D. Yang, J. Qian, M. Parrot, Earthq. Sci. 24, 549 (2011)

82. G. Occhipinti, P. Lognonné, E.A. Kherani, H. Hébert, Geophys. Res. Lett. 33, L20104 (2006)

83. J.-Y. Liu, Y.-B. Tsai, K.-F. Ma, Y.-I. Chen, H.-F. Tsai, C.-H. Lin, M. Kamogawa, C.-P. Lee, J. Geophys. Res. 111, A05303 (2006)

84. D. Píša, F. Němec, O. Santolík, M. Parrot, M. Rycroft, J. Geophys. Res.: Space Phys. 118, $5286(2013)$

85. X. Yan, X. Shan, X. Zhang, C. Qu, J. Tang, F. Wang, S. Wen, J. Appl. Remote Sens. 7, $073532(2013)$

86. J. Blecki, M. Parrot, R. Wronowski, Int. J. Remote Sens. 31, 3615 (2010)

87. J. Liu, X.B. Du, J. Zlotnicki, Y.-Y. Fan, Z.H. An, T. Xie, G.L. Zheng, D.C. Tan, J.Y. Chen, Chinese J. Geophys. 54, 828 (2011)

88. S.N. Walker, V. Kadirkamanathan, O.A. Pokhotelov, Ann. Geophys. 31, 1597 (2013)

89. Z. An, X. Du, Y. Fan, J. Liu, D. Tan, J. Chen, T. Xie, Chin. J. Geophys. 54, 2876 (2011)

90. Q. Li, A. Schekotov, T. Asano, M. Hayakawa, Open J. Earthquake Res. 4, 55 (2015)

91. M. Hayakawa, A. Schekotov, S. Potirakis, K. Eftaxias, Q. Li, T. Asano, Open J. Earthquake Res. 4, 85 (2015)

92. Y. Fan, X. Du, Z. An, J. Liu, D. Tan, J. Chen, Acta Geophys. 63, 679 (2015) 
93. Z. Ouyang, H. Zhang, Z. Fu, B. Gou, W. Jiang, Acta Geol. Sin. 83, 834 (2009)

94. M. Akhoondzadeh, Adv. Space Res. 55, 1754 (2015)

95. N.D. Ganguly, J. Atmos. Sol.-Terr. Phys. 140, 16 (2016)

96. A.A. Namgaladze, M.I. Karpov, Russian J. Physic. Chem. B 9, 754 (2015)

97. A.A. Namgaladze, Russian J. Phys. Chem. B 7, 589 (2013)

98. N. Genzano, C. Aliano, C. Filizzola, N. Pergola, V. Tramutoli, Tectonophysics 431, $197(2007)$

99. V. Tramutoli, C. Aliano, R. Corrado, C. Filizzola, N. Genzano, M. Lisi, G. Martinelli, N. Pergola, Chem. Geol. 339, 157 (2013)

100. Y. Zhou, Y. Wu, X. Qiao, X. Zhang, J. Atmos. Sol.-Terr. Phys. 71, 959 (2009)

101. D. Ouzounov, S. Pulinets, A. Romanov, A. Romanov Jr., K. Tsybulya, D. Davydenko, M. Kafatos, P. Taylor, Earthquake Sci. 24, 557 (2011) 